Article

\title{
Prediction of Potential Evapotranspiration Using Temperature-Based Heuristic Approaches
}

\author{
Rana Muhammad Adnan ${ }^{1} \mathbb{D}$, Salim Heddam ${ }^{2} \mathbb{D}$, Zaher Mundher Yaseen ${ }^{3} \mathbb{D}$, Shamsuddin Shahid ${ }^{4} \mathbb{D}$, \\ Ozgur Kisi ${ }^{4,5, *(D)}$ and Binquan Li ${ }^{1, *(D)}$
}

1 State Key Laboratory of Hydrology-Water Resources and Hydraulic Engineering, Hohai University, Nanjing 210098, China; rana@hhu.edu.cn

2 Faculty of Science, Agronomy Department, Hydraulics Division, University of Skikda, Skikda 21000, Algeria; heddamsalim@yahoo.fr

3 Institute of Research and Development, Duy Tan University, Da Nang 550000, Vietnam; zahermundheryaseen@duytan.edu.vn

4 Faculty of Engineering, School of Civil Engineering, Universiti Teknologi Malaysia (UTM), Johor Bahru 81310, Malaysia; sshahid@utm.my

5 School of Technology, Ilia State University, Tbilisi 0162, Georgia

* Correspondence: ozgur.kisi@iliauni.edu.ge (O.K.); libinquan@hhu.edu.cn (B.L.)

Citation: Adnan, R.M.; Heddam, S.; Yaseen, Z.M.; Shahid, S.; Kisi, O.; Li, B. Prediction of Potential

Evapotranspiration Using Temperature-Based Heuristic Approaches. Sustainability 2021, 13, 297. https://doi.org/10.3390/ su13010297

Received: 10 December 2020 Accepted: 24 December 2020 Published: 31 December 2020

Publisher's Note: MDPI stays neutral with regard to jurisdictional clai$\mathrm{ms}$ in published maps and institutional affiliations.

Copyright: (C) 2020 by the authors. Licensee MDPI, Basel, Switzerland. This article is an open access article distributed under the terms and conditions of the Creative Commons Attribution (CC BY) license (https:// creativecommons.org/licenses/by/ $4.0 /)$.

\begin{abstract}
The potential or reference evapotranspiration $\left(E T_{0}\right)$ is considered as one of the fundamental variables for irrigation management, agricultural planning, and modeling different hydrological $\mathrm{pr}^{\circ}$ Cesses, and therefore, its accurate prediction is highly essential. The study validates the feasibility of new temperature based heuristic models (i.e., group method of data handling neural network (GMDHNN), multivariate adaptive regression spline (MARS), and M5 model tree (M5Tree)) for estimating monthly $E T_{0}$. The outcomes of the newly developed models are compared with empirical formulations including Hargreaves-Samani (HS), calibrated HS, and Stephens-Stewart (SS) models based on mean absolute error (MAE), root mean square error (RMSE), and Nash-Sutcliffe efficiency. Monthly maximum and minimum temperatures $\left(T_{\max }\right.$ and $\left.T_{\min }\right)$ observed at two stations in Turkey are utilized as inputs for model development. In the applications, three data division scenarios are utilized and the effect of periodicity component (PC) on models' accuracies are also examined. By importing PC into the model inputs, the RMSE accuracy of GMDHNN, MARS, and M5Tree models increased by $1.4 \%, 8 \%$, and $6 \%$ in one station, respectively. The GMDHNN model with periodic input provides a superior performance to the other alternatives in both stations. The recommended model reduced the average error of MARS, M5Tree, HS, CHS, and SS models with respect to RMSE by $3.7-6.4 \%, 10.7-3.9 \%, 76-75 \%, 10-35 \%$, and $0.8-17 \%$ in estimating monthly $E T_{0}$, respectively. The HS model provides the worst accuracy while the calibrated version significantly improves its accuracy. The GMDHNN, MARS, M5Tree, SS, and CHS models are also compared in estimating monthly mean $E T_{0}$. The GMDHNN generally gave the best accuracy while the CHS provides considerably over/under-estimations. The study indicated that the only one data splitting scenario may mislead the modeler and for better validation of the heuristic methods, more data splitting scenarios should be applied.
\end{abstract}

Keywords: potential evapotranspiration; heuristic models; empirical formulation; hydrological processes; water management and sustainability

\section{Introduction}

Reference evapotranspiration $\left(E T_{0}\right)$ is one of the major components in the hydrological cycle [1]. It contributes to a rationale water resources management [2,3], and it is important in agriculture for measuring crop water requirement quantification [4]. In addition, $E T_{0}$ is used as inputs for several hydrological models, and adopted for climate change studies [5]. Several empirical and semi-empirical methods have been developed 
at different time scales for $E T_{0}$ prediction. The performance of the methods varies with respect to the meteorological variables included in the methods, ranging from temperature based, radiation based, and combination methods [6]. One of the earliest methodologies, the ET0 calculated using the standards FAO56 Penman-Monteith, has been adopted as a reference approach [7]. However, ET0 can be measured directly using lysimeters [2]. Measurement of ET0 is varied from one region to another and that is totally based on the regional climate characteristics [8]. Hence, empirical formulation is demonstrated as a remarkable limitation on the ET0 estimation. During the last few decades, models based on computer aid capacity indicated a distinguished progress in the hydrology and water resources fields [9-13]. Artificial intelligence (AI) models have been extensively applied as a reliable soft computing technology for ETO estimation based on the available and measured climatic variables [14-16].

A review of the literature indicates that numerous studies have examined the application of several AI models for estimating $E T_{0}$ [17-28]. In more detailed state-of-the-art, Yin et al. [26] introduced a new hybrid AI model dependent on the hybridization of a genetic algorithm with a kernel model i.e., a support vector machine (GA-SVM) for modeling daily $E T_{0}$ in China using several daily climatic variables including $T_{\max }, T_{\min }$, wind speed $\left(\mathrm{U}_{2}\right)$, relative humidity $(\mathrm{RH})$, and solar radiation (SR). Compared to classical an artificial neural network (ANN) and the SVM models, the scholars demonstrated the superiority of the GA-SVM in predicting $E T_{0}$. Jovic et al. [17] proposed a hybrid method called genetic programming (GP) for estimating $E T_{0}$ using eight climatic variables. Mattar [20] applied gene expression programming (GEP) for modeling monthly $E T_{0}$ in Egypt, using five input variables $T_{\max }, T_{\min }, \mathrm{RH}, \mathrm{U}_{2}$ and Rs. Tao et al. [25] introduced a hybrid method called adaptive neuro-fuzzy inference systems (ANFIS) with a firefly algorithm (FA) (ANFIS-FA) for modeling daily $E T_{0}$ at Burkina Faso. Using six input variables namely, $T_{\max }, T_{\min }$, maximum relative humidity $\left(\mathrm{RH}_{\max }\right), \mathrm{Rs}, \mathrm{U}_{2}$, and vapor pressure deficit (VP), the authors demonstrated that the FA significantly increased the exactness of the ANFIS method, and that the hybrid ANFIS-FA provided high accuracy with a determination coefficient $\left(\mathrm{R}^{2}\right)$ nearly equal to 0.97 compared to a $\mathrm{R}^{2}$ of 0.91 obtained using standard ANFIS. Using data from India, Adamala [27] compared four models in predicting daily $E T_{0}$, using fewer inputs variables: $T_{\max }, T_{\min }$, and extra-terrestrial radiation $(\mathrm{Ra})$. The applied models were a wavelet neural network (W-ANN), ANN, multi linear regression (MLR), and wavelet linear regression (W-MLR). The authors reported that decomposition of the input variables applying wavelet transform significantly improved the performance of the models with Nash-Sutcliffe efficiency (NSE) equal to 0.82. Using $T_{\max }, T_{\min }, \mathrm{RH}, \mathrm{U}_{2}, \mathrm{Rs}$, and sunshine hours (SH), Gavili et al. [28] demonstrated that ANN model was better than GEP and ANFIS for predicting monthly $E T_{0}$ in Iran, with a NSE value that reached 0.98 during the testing phase for all tested stations. Khoshravesh et al. [19] compared three regression methods, namely multivariate fractional polynomial (MFP), Bayesian (BR), and robust regressions (RBR) for modeling monthly $E T_{0}$ in Iran, using $T_{\max }, T_{\min }$, mean temperature ( $\left.T_{\text {mean }}\right)$, and Rs. Karbasi [29] built a new Gaussian process regression (GPR) for forecasting daily $E T_{0}$ several days in advance and demonstrated that the use of wavelet decomposition significantly increased the abilities of the methods and the RMSE dropped from $0.816 \mathrm{~mm}$ to $0.068 \mathrm{~mm}$.

Among several machine learning models explored over the literature, the group method of data handling type neural network (GMDHNN) is an dependent on the Rosenblatt's perceptron method introduced by Farlow [30]. GMDHNN is successfully applied in diverse engineering applications [31-34]. Within hydrology and water resources related research, Najafzadeh et al. [35] developed the GMDHNN model for scour depth (SD) of pipelines estimation due to waves variability; the prediction of local SD at bridge abutments in coarse sediments with thinly armored beds was conducted by Najafzadeh et al. [36]; simulation of flow discharge of straight compound channels was reported by Najafzadeh and Zahiri [37]; prediction of significant wave height was established by Shahabi et al. [38]; prediction of turbidity considering daily rainfall and discharge data was determined by Tsai 
and Yen [39]; an improved modeling of the discharge coefficient for triangular labyrinth lateral weirs was described by Parsaie and Haghiabi [40]; an evaluation of treated water quality in a water treatment plant was carried out by Alitaleshi and Daghbandan [41]; a prediction of turbidity and the free residual aluminum of drinking water was tested by Daghbandan et al. [42]. Based on the reported literature review, only one study reported the implementation of the GMDHNN $E T_{0}$ modeling developed by da Silva Carvalho and Delgado [43]. The study conducted based on the calculated FAO56 Penman-Monteith using only previous values and very limited data of daily scale over three years (January 2011 to January 2014), were utilized for the modeling development.

Multivariate adaptive regression splines (MARS) model introduced by Friedman [44], and M5 tree (M5Tree) model established developed by Quinlan [45]. They are another distinguished category of a data driven model, which is mainly used in environmental, hydrology, irrigation, and hydraulic studies. The MARS model is one of the sophisticated AI models, as it has the ability to provide a non-parametric feature that is able to identify the actual relationship between predictors and predicted using splines method for detecting the nonlinearity pattern [46]. The MARS model has been successfully applied in many hydrological applications [47-52]. The MARS model was successfully used to predict water pollution by Kisi and Parmar [47], to forecast sediment load by Adnan et al. [48], to model daily streamflow by Yin et al. [49], to predict evaporation by Ghaemi et al., [50], and to predict monthly river flow by Adnan et al. [51].

However, fewer applications related to the $E T_{0}$ modeling can be seen in the related literature. For instance, Mehdizadeh et al. [53] compared MARS, SVM, and GEP for modeling monthly $E T_{0}$ in Iran, using several climatic variables as inputs: $T_{\max }, T_{\min }$, $\mathrm{T}_{\text {mean }}, \mathrm{RH}, \mathrm{U}_{2}, \mathrm{VP}, \mathrm{Ra}, \mathrm{Rs}$, and $\mathrm{Rn}$. The authors have compared several scenarios, namely temperature-based, radiation-based, mass transfer-based, and meteorological parametersbased scenarios. For the temperature-based scenarios, using only $T_{\max }, T_{\min }$, and $\mathrm{Ra}$, the research finding approved the potential of MARS model over the SVM and GEP with a $\mathrm{R}^{2}$ equal to 0.944 in the validation phase. Mehdizadeh et al. [22] investigated the capacity of MARS and GEP models for estimating daily $E T_{0}$ in Iran using four climatic variables: $\mathrm{T}_{\text {mean }}, \mathrm{RH}, \mathrm{U}_{2}$, and Rs. The author demonstrated that the MARS model performed the best using all climate variables with a $R^{2}$ nearly equal to 0.99 in the validation phase. Using four climatic variables, namely, $\mathrm{T}_{\text {mean }}, \mathrm{RH}, \mathrm{U}_{2}$, and Rs, Kisi [54] compared MARS, M5Tree and least square support vector machines (LSSVM) for modeling monthly $E T_{0}$ in Turkey. The authors demonstrated that in some cases, MARS is superior over the two others in terms of performance accuracy. Keshtegar et al., [55] and Keshtegar and Kisi, [56] applied the M5Tree, ANFIS, and ANN for modeling daily $E T_{0}$ in Turkey, using $\mathrm{T}_{\text {mean }}, \mathrm{RH}, \mathrm{U}_{2}$, and Rs as input variables. Kisi and Kilic [57] compared M5Tree and ANN for modeling daily $E T_{0}$ in USA, using $\mathrm{T}_{\text {mean }}, \mathrm{RH}, \mathrm{U}_{2}$, and Rs. Rahimikhoob [58] compared M5Tree and ANN for modeling monthly $E T_{0}$ in USA, using $\mathrm{T}_{\text {mean }}, \mathrm{RH}, \mathrm{U}_{2}$, and $\mathrm{Ra}$, in Iran. The authors reported that both methods produced almost similar estimates with smaller differences.

The majority of the aforementioned studies have been conducted using several input variables. With the exception of the investigation by Mehdizadeh et al. [53], in which the MARS model was applied for modeling $E T_{0}$ using only temperature data as inputs, there are limited studies that have applied MARS and M5Tree models for $E T_{0}$ utilizing only temperature inputs. Hence, the major objective of the present investigation was to assess the performances of GMDHNN, MARS, and M5Tree models to estimate $E T_{0}$ using only temperature and extra-terrestrial radiation and validating the results against the empirical formulations (i.e., HS, CHS and SS). The main motivation of the current study is using specific climate data (temperature) to simulate the $E T_{0}$, as this involves highly essential and significant factors influencing $E T_{0}$, while recording of such data for long durations is an easy task in developing countries. The other difference of this study compared to previous ones is the use of different data splitting scenarios and the inclusion of periodicity (month number of the year) as an input to the GMDHNN, MARS, and M5Tree models. 


\section{Materials and Methods}

\subsection{Case Study}

In the present study, monthly maximum and minimum temperatures ( $T_{\max }$ and $T_{\min }$ ), solar radiation, relative humidity, and wind speed measured at Adana (latitude $37^{\circ} 00^{\prime}$ $\mathrm{N}$, longitude $35^{\circ} 19^{\prime} \mathrm{E}$, altitude $27 \mathrm{~m}$ ) and Antakya (latitude $36^{\circ} 33^{\prime} \mathrm{N}$, longitude $36^{\circ} 30^{\prime} \mathrm{E}$, altitude $100 \mathrm{~m}$ ) stations in the Mediterranean Region of Turkey were utilized. The stations operated by the Turkish Meteorological Organization can be observed from Figure 1. The data periods used for the Adana and Antakya are 1968-2015 and 1983-2010, respectively. The statistical parameters of the data employed in the applications are summed up in Table 1. $R_{a}$ has the highest correlation with $E T_{0}$ followed by the $T_{\min }$ and $T_{\max }$ and $\mathrm{R}_{\mathrm{a}}$ has a higher correlation with $E T_{0}$ in Antakya compared to Adana. It is also visible from Table 1 that $E T_{0}$ in Adana is higher than for Antakya.

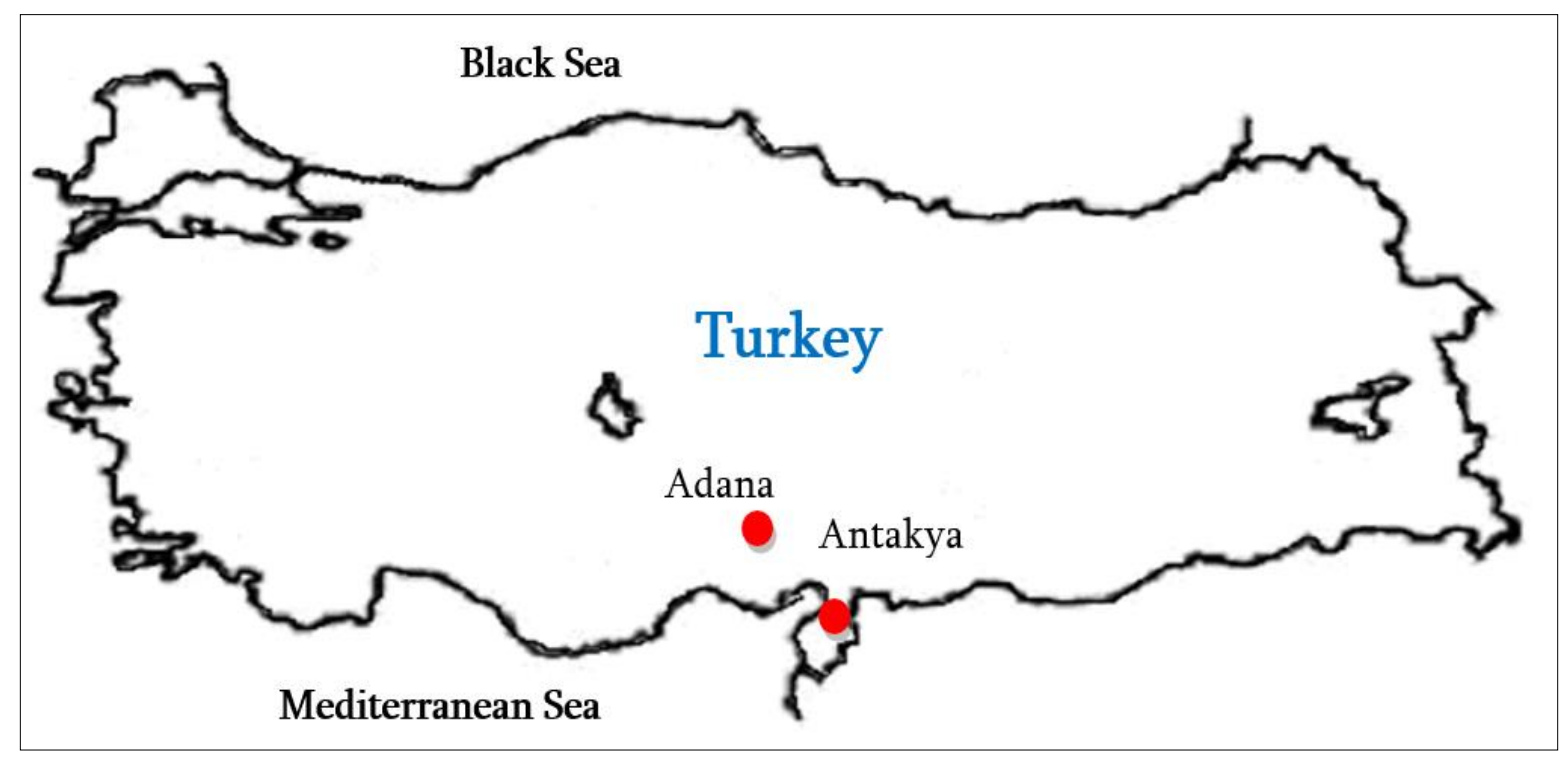

Figure 1. The location of the Adana and Antakya stations.

Table 1. The statistical parameters of climatic data used in the study.

\begin{tabular}{cccccccc}
\hline Station & Variable & $\mathbf{x}_{\text {min }}$ & $\mathbf{x}_{\text {max }}$ & $\mathbf{x}_{\text {mean }}$ & $\mathbf{S}_{\mathbf{x}}$ & $\mathbf{C}_{\mathbf{s x}}$ & Correlation with $\boldsymbol{E T}_{\mathbf{0}}$ \\
\hline \multirow{5}{*}{ Adana } & $T_{\min }\left({ }^{\circ} \mathrm{C}\right)$ & -3.4 & 23.4 & 9.33 & 7.70 & 0.08 & 0.828 \\
& $T_{\max }\left({ }^{\circ} \mathrm{C}\right)$ & 17.0 & 44.0 & 31.3 & 7.02 & -0.41 & 0.850 \\
& $\mathrm{R}_{\mathrm{a}}\left(\mathrm{MJ} / \mathrm{m}^{2}\right)$ & 15.5 & 41.7 & 29.4 & 9.35 & -0.14 & 0.920 \\
& $E T_{0}(\mathrm{~mm})$ & 0.57 & 6.52 & 3.32 & 1.52 & 0.04 & 1.000 \\
\hline \multirow{5}{*}{ Antakya } & $T_{\min }\left({ }^{\circ} \mathrm{C}\right)$ & -4.6 & 24.8 & 9.18 & 8.16 & 0.22 & 0.860 \\
& $T_{\max }\left({ }^{\circ} \mathrm{C}\right)$ & 14.4 & 42.6 & 28.8 & 7.64 & -0.32 & 0.878 \\
& $\mathrm{R}_{\mathrm{a}}\left(\mathrm{MJ} / \mathrm{m}^{2}\right)$ & 16.0 & 41.6 & 29.5 & 9.16 & -0.11 & 0.926 \\
& $E T_{0}(\mathrm{~mm})$ & 0.28 & 7.20 & 3.39 & 1.86 & 0.06 & 1.000 \\
\hline
\end{tabular}

$T_{\min }, T_{\max }, \mathrm{R}_{\mathrm{a}}$, and $E T_{0}$ are minimum and maximum temperatures, extraterrestrial radiation, and reference evapotranspiration, respectively. $x_{\min }, x_{\max }, x_{\text {mean }}, S_{x}$, and $C_{s x}$ are minimum, maximum, mean, standard deviation, and skewness, respectively.

\subsection{Group Method of Data Handling Type Neural Network}

GMDHNN is a powerful machine learning tool based upon the principle of termination. In this principle, the system follows the one process through data importing, rearing, hybridizing, choice, and rejection. The GMDH algorithm is divided into two parts: one is the parameter and other is the non-parameter. If the variance is low, then parametric algorithms provide the best results and for high variance, non-parametric algorithms perform better. The GMDHNN model is capable of handling the multiple input variables and 
provides single output. There are different layers in the GMDHNN model, which have a set of neurons; these neurons are further linked with quadratic polynomial in every layer, which provides the new neurons for the next layer [59-61]. The output of the database with multiple input variables and $M$ numbers of observations is defined as below.

$$
m_{i}=f\left(y_{i, 1}, y_{i, 2}, y_{i, 3}, \ldots, y_{i, M}\right) \quad(i=1,2,3,4, \ldots, N)
$$

Here, $\left(y_{1}, y_{2}, y_{3}, y_{4}, \ldots, y_{M}\right)$ is the real input of the mapping $f$ and $m_{i}$ is the real output based upon the real input. For the identification of the problem, $\hat{f}$ is considered as mapping instead of $f$ to forecast the $\hat{m}$ (output value) instead of $m$, and this $\hat{m}$ is close to $m$. The provided input $\left(y_{1}, y_{2}, y_{3}, y_{4}, \ldots, y_{M}\right)$ is used for the GMDHNN training to attain the output $\hat{m}_{i}$ as given below.

$$
\hat{m}_{i}=\hat{f}\left(y_{i, 1}, y_{i, 2}, y_{i, 3}, \ldots, y_{i, M}\right) \quad(i=1,2,3, \ldots, N)
$$

The GMDH-NN algorithm is working to minimize the MSE (mean square error) for making the model most effective for prediction. This MSE is calculated as $E$ below to make the error level reach its minimum.

$$
\left.\left\langle E=\left\{\sum_{i=1}^{N}\left[\hat{f}\left(y_{i, 1}, y_{i, 2}, y_{i, 3}, \ldots, y_{i, M}\right)-y_{i}\right)\right]^{2}\right\} / N \rightarrow \min \right\rangle
$$

As we discussed above, neurons are connected with the quadratic polynomial, while Kolmogorov-Gabor polynomial is used to conduct relation mapping between input and output variables $[53,55,56]$. This Kolmogorov-Gabor polynomial can be expressed as below

$$
m=d_{0}+\sum_{i=1}^{M} d_{i} y_{i}+\sum_{i=1}^{M} \sum_{j=1}^{M} d_{i j} y_{i} y_{j}+\sum_{i=1}^{M} \sum_{j=1}^{M} \sum_{k=1}^{M} d_{i j k} y_{i} y_{j} y_{k}+\ldots
$$

To minimize the variation between the actual output $(m)$ and estimated output $(\hat{m})$, a regression model is applied for each pair of input variables $\left(y_{i}, y_{j}\right)$.

\subsection{Multivariate Adaptive Regression Splines}

The Multivariate adaptive regression splines model (MARS) was proposed by Friedman [44] as a new data driven technique, looking for any possible nonlinear and nonparametric relationship which can exist and can be built between a set of inputs and output variables. MARS is used to try to identify and automatically establish the possible explicit regression equation between the regressors and the dependent variables in a stepwise manner; another important advantage of the MARS model is its abilities to provide the part of the contribution of each predictor to the dependent variable, and at the end of the training procedure it provides the final rankings of the regressors individually based on its rank [44]. A wide range of applications of the MARS model can be found in the literature including: estimating heating load in buildings [62,63], predicting centerline segregation in steel cast products [64], predictions of landslide susceptibility [65], estimating fractional snow cover (FSC) from MODIS data [66], and predicting monthly discharge and mean soil temperature [22,62]. Using the MARS model, the space of regressors is divided into several subspaces called knots, each has its own function and splines (segments) which are used to link all these knots, and all the spline are grouped to form a basis function $(B F)$. Hence, globally speaking, the MARS model is based on three major clear and precise components: knots, spline, and $B F$, and the development of the model is achieved in two phases: forward (building) and backward (pruning) phases. In the forward phase, a high dimensional model is built that contains the chosen knots and their corresponding $B F$. During the backward phase, the $B F$ that provides fewer contributions to the decreasing of the error is pruned via generalized cross-validation (GCV) [66].

Firstly, MARS starts by building a set of BF with the following equation [44]:

$$
B F_{m}(x)=\max (0, c-x) \text { or } B F_{m}(x)=\max (0, x-c)
$$


where $x$ is one of the regressor variables, $c$ is the threshold value for the regressor $x$, and the $B F$ is the basis function. Consequently, the MARS model is developed as an ensemble of the $B F$ as follow:

$$
Y=f(x)=\psi_{0}+\sum_{m=1}^{M} \psi_{m} B F_{m}(x) .
$$

$Y$ is the response (dependent) variable $\left(E T_{0}\right), B F$ is the basis function, $x$ is a regressor that contributing to the formation of the $B F$, and $\psi_{m}$ are unknown coefficients of the $m t h$ $B F$, while $M$ is the total number of the $B F[44,66]$. The GCV is expressed as follow:

$$
G C V(M)=\frac{\frac{1}{N} \sum_{i=1}^{N}\left(y_{i}-f\left(x_{i}\right)\right)^{2}}{\left(1-\frac{c(M)}{N}\right)^{2}}
$$

$N$ is the quantity of the pattern, $M$ presents the BF number, $y_{i}$ is the targeted variable $\left(E T_{0}\right), f\left(x_{i}\right)$ is the predicted value of the pattern $i$, and $c(M)$ is the penalty factor [67]. The MARS model was implemented utilizing the MatLab toolbox ARESLab [68].

\subsection{M5 Model Tree}

The M5 model tree (M5Tree), which is an amended version of the original decision tree (DT), was proposed by Quinlan [45]. DT was originally proposed for solving classification problems using a splitting method, for which the available information from the data is extracted via the construction of a tree composed of three kinds of nodes: the internal, the roots, and the leaves nodes [45]. The M5Tree has been used for solving several problems, such as predictions of energy consumption in buildings [69], air quality modeling [70], predicting liquefaction-induced lateral spreading [71], forecasting solar ultraviolet [72], and predicting daily water levels in rivers [73]. The M5Tree is a regression model in which the training data are being apportioned to smaller subsets through the construction of a tree and using a gain ratio criterion, an individual regression model is built for each subset [45]. Once the tree had been constructed, the training process starts and tries to determine the best separation to different subsets with respect to two conditions: (i) the leaves nodes of the tree only contains patterns from one subset or (ii) separation does not occur until any improvement in the gain ratio is observed. For a given $n$ number of nodes leaves corresponding to $k$ breaking points, each subset has its own linear model as follow [73]:

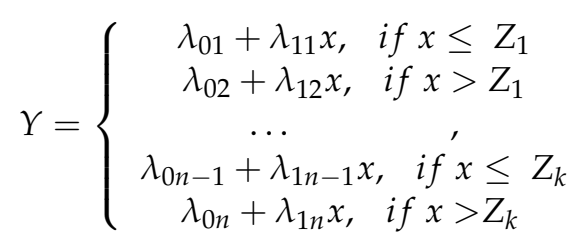

where $Y$ is the calculated $E T_{0}, x$ is one of the input variables selected for model development (climatic variables), $\lambda_{01}$ and $\lambda_{1 i}(i=1: n)$ are the parameters of the linear models at $n$ leave, and $Z_{1: k}$ are the breaking points values. According to Quinlan [45], building an M5Tree model generally takes two major steps: the growth step (create a DT) and the tree pruning step to prune back an overgrown tree. The standard deviation reduction (SDR) statistical metric was used to compute the error at each node as the splitting criterion $[74,75]$ :

$$
S D R=s d(T)-\sum \frac{\left|T_{i}\right|}{|T|} s d\left(T_{i}\right) .
$$

$T_{i}$ indicates the subset of the $i$ th possible test, $T$ represents the examples number reaching the node, and $s d$ is the standard deviation of the observations. The M5Tree is applied utilizing the MATLAB toolbox M5PrimeLab [76].

\subsection{Stephens-Stewart Model}

Stephens and Stewart's [77] method is used for pan evaporation estimation. It can be expressed as

$$
E_{\text {pan }}=R\left(a+b T_{\text {mean }}\right)
$$


where $E_{\text {pan }}$ is daily pan evaporation ( $\left.\mathrm{mm} / \mathrm{month}\right), R$ is solar radiation ( $\mathrm{mm} / \mathrm{month}$ ) at daily scale, and $a$ and $b$ refer the fitted parameters. In the present study, the SS method given in Equation (9) was used for $E T_{0}$ estimation by using extraterrestrial radiation instead of solar radiation data:

$$
E T_{0}=R a\left(a+b T_{\text {mean }}\right)
$$

where $E T_{0}$ denotes the reference evapotranspiration $(\mathrm{mm} / \mathrm{month})$ and $R a$ refers the extraterrestrial radiation $(\mathrm{mm} / \mathrm{month})$.

\subsection{Hargreaves and Samani Model}

Hargreaves and Samani (HS) $[78,79]$ is a temperature-based model and need only fewer input variables: extraterrestrial radiation ( $\mathrm{Ra})\left(\mathrm{mm} /\right.$ day), $T_{\max }$ and $T_{\min }\left({ }^{\circ} \mathrm{C}\right)$ :

$$
E T_{0}=0.0023 R_{a}\left(T_{\text {mean }}+17.8\right)\left(T_{\max }-T_{\min }\right)^{0.5}
$$

where $T_{\max }$ and $T_{\min }$ are the monthly maximum and minimum temperatures $\left({ }^{\circ} \mathrm{C}\right)$, respectively. The calibrated version of HS given in the following equation was also employed in this study:

where $a$ and $b$ are fitted parameters.

$$
E T_{0, \quad \text { calibrated }}=a+b E T_{0}
$$

\subsection{Model Development by Heuristic Methods}

In the presented study, three abovementioned heuristic methods were implemented for monthly $E T_{0}$ estimation. Three different data division scenarios: $50-50 \%, 60-40 \%$, and $75-25 \%$, were employed in the applications so as to see the effect of training/test size on models' accuracy. It is well-known that data-driven methods are highly affected by the size of the training data and that more data generally produce a better model. As also mentioned in the introduction section, the studies in the existing literature generally utilize four climatic inputs: air temperatures $\left(T_{\max }, T_{\min }\right)$, wind speed $\left(\mathrm{U}_{2}\right)$, relative humidity $(\mathrm{RH})$, and solar radiation (SR) in $E T_{0}$ estimation. In developing countries, measurement of all these variables is always not possible and therefore models requiring a limited number of inputs are necessary in such cases. As was also reported by a recent review [1], future studies are required for developing new models with limited inputs. Keeping this in the mind, the following two input combinations were considered in this study:

$T_{\min }, T_{\max }, \mathrm{R}_{\mathrm{a}}$

$T_{\min }, T_{\max }, R_{a}, \alpha$.

It is worth mentioning that the air temperature is easily available in every place and that $R_{a}$ can be calculated using the Julia date. The developed models are be useful in practical applications because they only need a smaller number of input variables. The periodicity ( $\alpha$, month number of the year) was also considered in the model input to see its influence on models' exactness if there is any. The flowchart provided in Figure 2 summarizes the model development procedure.

In the applications, GMDHNN, MARS, and M5Tree heuristic methods were employed to estimate monthly $E T_{0}$ while only utilizing temperature data as model inputs. Data of two stations, Adana and Antakya, were used for calibration of the methods. First, monthly $E T_{0}$ values were calculated by the FAO-56 PM formula using data of minimum and maximum temperatures, relative humidity, solar radiation, and wind speed following the guideline of Allen et al. [7]. Then, the obtained $E T_{0}$ data were used for the calibration and test of the selected models. The outcomes of GMDHNN, MARS, and M5Tree methods were compared with the empirical HS, calibrated HS (CHS), and SS regression methods. 
Dividing data into two parts, train-test as $50 \%-50 \%$ or $60 \%-40 \%$ or $75 \%-25 \%$

』)
Enter the inputs $\left(\mathrm{T}_{\min }, \mathrm{T}_{\max }, \mathrm{R}_{\mathrm{k}}, \alpha\right)$ and output $\left(\mathrm{ET}_{0}\right)$ data of training set for obtaining parameters of the selected model (GMDHNN, MARS, M5Tree)



Figure 2. Flowchart of the proposed heuristic models.

\section{Application and Results}

The models were evaluated with respect to three commonly used statistics: root mean square error (RMSE), mean absolute error (MAE), and Nash-Sutcliffe efficiency (NSE) [80-82]. RMSE and MAE varied from 0 to positive infinity. RMSE and MAE outcomes equivalent to 0 indicate a perfect fit. NSE varies from negative infinity to 1 and 1 means that models perfectly catch the observed values. The expressions of the RMSE, MAE, and NSE are:

$$
\begin{aligned}
R M S E & =\sqrt{\frac{\sum_{i=1}^{N}\left(E T_{0, i}-E T_{0, i M}\right)^{2}}{N}} \\
M A E & =\frac{\sum_{i=1}^{N}\left|E T_{0, i}-E T_{0, i M}\right|}{N}
\end{aligned}
$$




$$
N S E=1-\frac{\sum_{i=1}^{N}\left(E T_{0, i}-E T_{0, i M}\right)^{2}}{\sum_{i=1}^{N}\left(E T_{0, i}-\overline{E T}_{0}\right)^{2}} .
$$

In the equations, $N$ is the quantity of data, $\overline{E T}_{0}$ is average value of the reference evapotranspiration computed by FAO-56 PM, $E T_{0, i M}$ is estimated $E T_{0}$, and $E T_{0, i}$ is computed reference evapotranspiration.

For Adana Station, GMDHNN, MARS, M5Tree, HS, CHS, and SS models are compared in Table 2 while considering RMSE, MAE, and NSE statistics. In the table, training and testing accuracies can be observed for three different train-test scenarios. In the three implemented heuristic methods, default structures were used and models were calibrated by introducing the training data; in case of the 1st, 2nd, and 3rd scenarios, 50\%, 60\%, and $75 \%$ of the whole data were utilized to obtain optimal parameters of the models. After calibration process, the calculated parameters of the GMDHNN, MARS, and M5Tree models were kept and they were directly used in the testing stage and models were validated by the test data; in case of the 1st, $2 \mathrm{nd}$, and $3 \mathrm{rd}$ scenarios, $50 \%, 40 \%$, and $25 \%$ of the whole data were utilized to assess the models' accuracies based on the three aforementioned statistics (RMSE, MAE, and NSE). GMDHNN2, MARS2, and M5Tree2 models were also developed by adding periodicity component $(\alpha)$ to the GMDHNN1, MARS1, and M5tree1 models so as to see its effect on models' accuracy in estimation $E T_{0}$. It is obvious that there was not any considerable effect of $\alpha$ on models' exactness in this station. M5Tree models had better fitting in the training stage whereas the GMDHNN and MARS models has a superior performance to the M5Tree in the testing stage. GMDHNN has a better accuracy than the MARS but the difference is not too large. The calibration process considerably increases the HS performance in the estimation of $E T_{0}$. Average statistics in Table 2 show that the GMDHNN and SS have almost the same performance and they show a superior performance to the other models with respect to three criteria. The relative differences between the GMDHNN/SS and MARS2 models with respect to average RMSE and MAE are $2.9 \%$ and 3\%, respectively. Detailed results indicate that a slight difference exists between periodic MARS (MARS2) and SS models in 50-50\% and $60-40 \%$ train-test scenarios, while the latter performs better than the first in a $75-25 \%$ scenario. These results tell us that the use of one data-splitting scenario may mislead modelers during evaluation of the methods' accuracy. The methods are also compared in Figure 3 with respect to RMSE and NSE in the testing stage. The variation of the criteria (RMSE, NSE) with respect to different splitting scenarios is parallel to each other for all of the applied methods. NSE decreases and RMSE slightly increases from the first splitting scenario $(50-50 \%)$ to the third scenario $(75-25 \%)$.

Table 2. Root mean square error (RMSE), Mean absolute error (MAE), and Nash-Sutcliffe efficiency (NSE) statistics of each model for different data splitting strategies-Adana.

\begin{tabular}{|c|c|c|c|c|c|c|c|}
\hline \multirow[b]{2}{*}{ Model } & \multirow[b]{2}{*}{ Input } & \multicolumn{3}{|c|}{ Training } & \multicolumn{3}{|c|}{ Test } \\
\hline & & $\begin{array}{c}\text { RMSE } \\
(\mathrm{mm})\end{array}$ & $\begin{array}{l}\text { MAE } \\
(\mathrm{mm})\end{array}$ & NSE & $\begin{array}{c}\text { RMSE } \\
(\mathrm{mm})\end{array}$ & $\begin{array}{l}\text { MAE } \\
(\mathrm{mm})\end{array}$ & NSE \\
\hline \multicolumn{8}{|c|}{$50 \%$ training and $50 \%$ test } \\
\hline MARS1 & $T_{\min }, T_{\max }, R_{a}$ & 0.454 & 0.363 & 0.908 & 0.467 & 0.359 & 0.907 \\
\hline MARS2 & $T_{\min }, T_{\max }, R_{a}, \alpha$ & 0.461 & 0.356 & 0.905 & 0.466 & 0.357 & 0.907 \\
\hline M5Tree1 & $T_{\min }, T_{\max }, \mathrm{R}_{\mathrm{a}}$ & 0.408 & 0.301 & 0.926 & 0.518 & 0.406 & 0.885 \\
\hline M5Tree2 & $T_{\min }, T_{\max }, R_{a}, \alpha$ & 0.408 & 0.301 & 0.926 & 0.518 & 0.406 & 0.885 \\
\hline HS & $T_{\min }, T_{\max }, \mathrm{R}_{\mathrm{a}}$ & 2.021 & 1.777 & -0.82 & 2.006 & 1.782 & -0.72 \\
\hline $\mathrm{CHS}$ & $T_{\min }, T_{\max }, R_{\mathrm{a}}$ & 0.523 & 0.407 & 0.878 & 0.510 & 0.383 & 0.889 \\
\hline SS & $T_{\min }, T_{\max }, R_{a}$ & 0.501 & 0.390 & 0.888 & 0.463 & 0.355 & 0.909 \\
\hline GMDHNN1 & $T_{\min }, T_{\max }, \mathrm{R}_{\mathrm{a}}$ & 0.448 & 0.353 & 0.898 & 0.456 & 0.347 & 0.895 \\
\hline GMDHNN2 & $T_{\text {min }}, T_{\text {max }}, R_{a}, \alpha$ & 0.443 & 0.347 & 0.901 & 0.453 & 0.343 & 0.898 \\
\hline
\end{tabular}


Table 2. Cont.

\begin{tabular}{|c|c|c|c|c|c|c|c|}
\hline \multirow[b]{2}{*}{ Model } & \multirow{2}{*}{ Input } & \multicolumn{3}{|c|}{ Training } & \multicolumn{3}{|c|}{ Test } \\
\hline & & $\begin{array}{c}\text { RMSE } \\
\text { (mm) }\end{array}$ & $\begin{array}{l}\text { MAE } \\
(\mathrm{mm})\end{array}$ & NSE & $\begin{array}{c}\text { RMSE } \\
(\mathrm{mm})\end{array}$ & $\begin{array}{l}\text { MAE } \\
(\mathrm{mm})\end{array}$ & NSE \\
\hline \multicolumn{8}{|c|}{$60 \%$ training and $40 \%$ test } \\
\hline MARS1 & $T_{\min }, T_{\max }, R_{\mathrm{a}}$ & 0.435 & 0.344 & 0.916 & 0.510 & 0.389 & 0.889 \\
\hline MARS2 & $T_{\min }, T_{\max }, R_{a}, \alpha$ & 0.447 & 0.347 & 0.912 & 0.492 & 0.376 & 0.898 \\
\hline M5Tree1 & $T_{\min }, T_{\max }, \mathrm{R}_{\mathrm{a}}$ & 0.402 & 0.288 & 0.929 & 0.529 & 0.406 & 0.881 \\
\hline M5Tree2 & $T_{\min }, T_{\max }, R_{a}, \alpha$ & 0.402 & 0.288 & 0.929 & 0.529 & 0.406 & 0.881 \\
\hline HS & $T_{\min }, T_{\max }, \mathrm{R}_{\mathrm{a}}$ & 2.048 & 1.809 & -0.86 & 1.960 & 1.734 & -0.63 \\
\hline CHS & $T_{\min }, T_{\max }, \mathrm{R}_{\mathrm{a}}$ & 0.509 & 0.396 & 0.885 & 0.527 & 0.395 & 0.882 \\
\hline SS & $T_{\min }, T_{\max }, R_{a}$ & 0.482 & 0.376 & 0.897 & 0.482 & 0.368 & 0.901 \\
\hline GMDHNN1 & $T_{\min }, T_{\max }, \mathrm{R}_{\mathrm{a}}$ & 0.428 & 0.331 & 0.909 & 0.480 & 0.368 & 0.902 \\
\hline GMDHNN2 & $T_{\min }, T_{\max }, R_{a}, \alpha$ & 0.424 & 0.327 & 0.910 & 0.478 & 0.366 & 0.903 \\
\hline \multicolumn{8}{|c|}{$75 \%$ training and $25 \%$ test } \\
\hline MARS1 & $T_{\min }, T_{\max }, \mathrm{R}_{\mathrm{a}}$ & 0.438 & 0.339 & 0.916 & 0.516 & 0.408 & 0.884 \\
\hline MARS2 & $T_{\min }, T_{\max }, \mathrm{R}_{\mathrm{a}}, \alpha$ & 0.437 & 0.336 & 0.917 & 0.522 & 0.405 & 0.882 \\
\hline M5Tree1 & $T_{\min }, T_{\max }, R_{\mathrm{a}}$ & 0.385 & 0.279 & 0.935 & 0.550 & 0.424 & 0.869 \\
\hline M5Tree2 & $T_{\min }, T_{\max }, R_{a}, \alpha$ & 0.385 & 0.279 & 0.935 & 0.550 & 0.424 & 0.869 \\
\hline HS & $T_{\min }, T_{\max }, R_{\mathrm{a}}$ & 2.053 & 1.821 & -0.841 & 1.894 & 1.659 & -0.556 \\
\hline CHS & $T_{\min }, T_{\max }, \mathrm{R}_{\mathrm{a}}$ & 0.504 & 0.388 & 0.889 & 0.552 & 0.414 & 0.868 \\
\hline SS & $T_{\min }, T_{\max }, \mathrm{R}_{\mathrm{a}}$ & 0.479 & 0.370 & 0.900 & 0.491 & 0.382 & 0.896 \\
\hline GMDHNN1 & $T_{\min }, T_{\max }, \mathrm{R}_{\mathrm{a}}$ & 0.421 & 0.322 & 0.914 & 0.497 & 0.385 & 0.881 \\
\hline GMDHNN2 & $T_{\min }, T_{\max }, R_{a}, \alpha$ & 0.420 & 0.320 & 0.915 & 0.495 & 0.384 & 0.883 \\
\hline \multicolumn{8}{|c|}{ Average } \\
\hline MARS1 & $T_{\min }, T_{\max }, \mathrm{R}_{\mathrm{a}}$ & 0.442 & 0.349 & 0.913 & 0.498 & 0.385 & 0.893 \\
\hline MARS2 & $T_{\min }, T_{\max }, R_{a}, \alpha$ & 0.448 & 0.346 & 0.911 & 0.493 & 0.379 & 0.896 \\
\hline M5Tree1 & $T_{\min }, T_{\max }, R_{a}$ & 0.398 & 0.289 & 0.930 & 0.532 & 0.412 & 0.878 \\
\hline M5Tree2 & $T_{\min }, T_{\max }, R_{a}, \alpha$ & 0.398 & 0.289 & 0.930 & 0.532 & 0.412 & 0.878 \\
\hline HS & $T_{\min }, T_{\max }, R_{\mathrm{a}}$ & 2.041 & 1.802 & -0.840 & 1.953 & 1.725 & -0.635 \\
\hline CHS & $T_{\min }, T_{\max }, \mathrm{R}_{\mathrm{a}}$ & 0.512 & 0.397 & 0.884 & 0.530 & 0.397 & 0.880 \\
\hline SS & $T_{\min }, T_{\max }, \mathrm{R}_{\mathrm{a}}$ & 0.487 & 0.379 & 0.895 & 0.479 & 0.368 & 0.902 \\
\hline GMDHNN1 & $T_{\min }, T_{\max }, R_{\mathrm{a}}$ & 0.432 & 0.335 & 0.907 & 0.478 & 0.367 & 0.893 \\
\hline GMDHNN2 & $T_{\min }, T_{\max }, R_{a}, \alpha$ & 0.429 & 0.331 & 0.909 & 0.475 & 0.364 & 0.895 \\
\hline
\end{tabular}

$T_{\min }, T_{\max }, \mathrm{R}_{\mathrm{a}}$ and $\alpha$ are minimum and maximum temperatures, extraterrestrial radiation, and periodicity (month number), respectively. RMSE, MAE, and NSE are the root mean square error, mean absolute error, and efficiency coefficient, respectively.

$$
\square 50 \%-50 \% \quad \square 0 \%-40 \% \quad \square 75 \%-25 \% \quad \text { Average }
$$

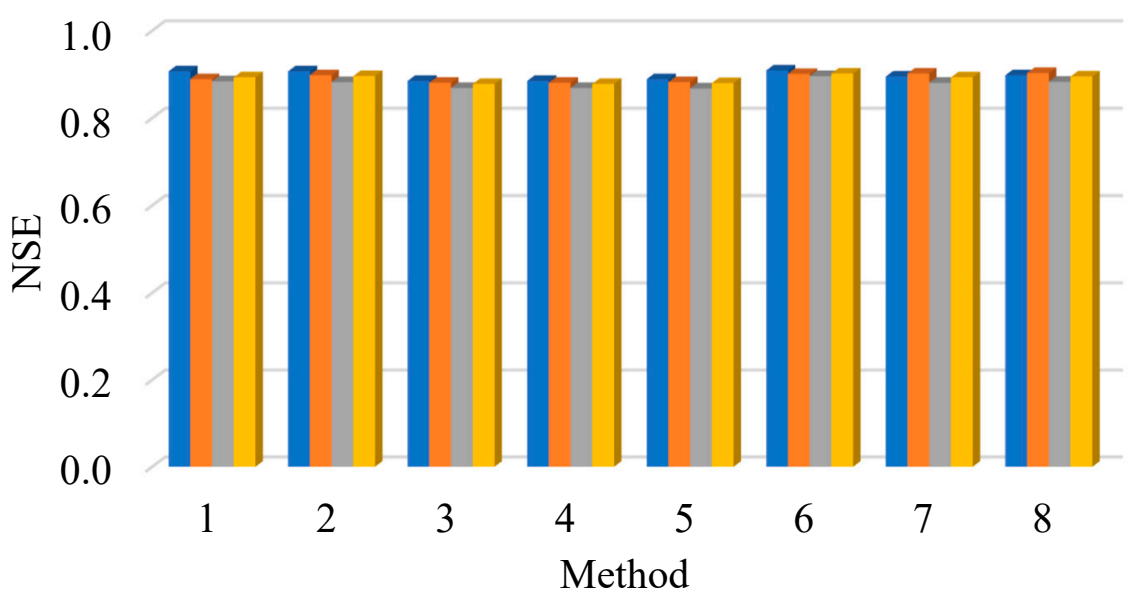

Figure 3. Cont. 


\section{$\square 50 \%-50 \% \quad \square 0 \%-40 \% \quad \square 75 \%-25 \% \quad$ Average}

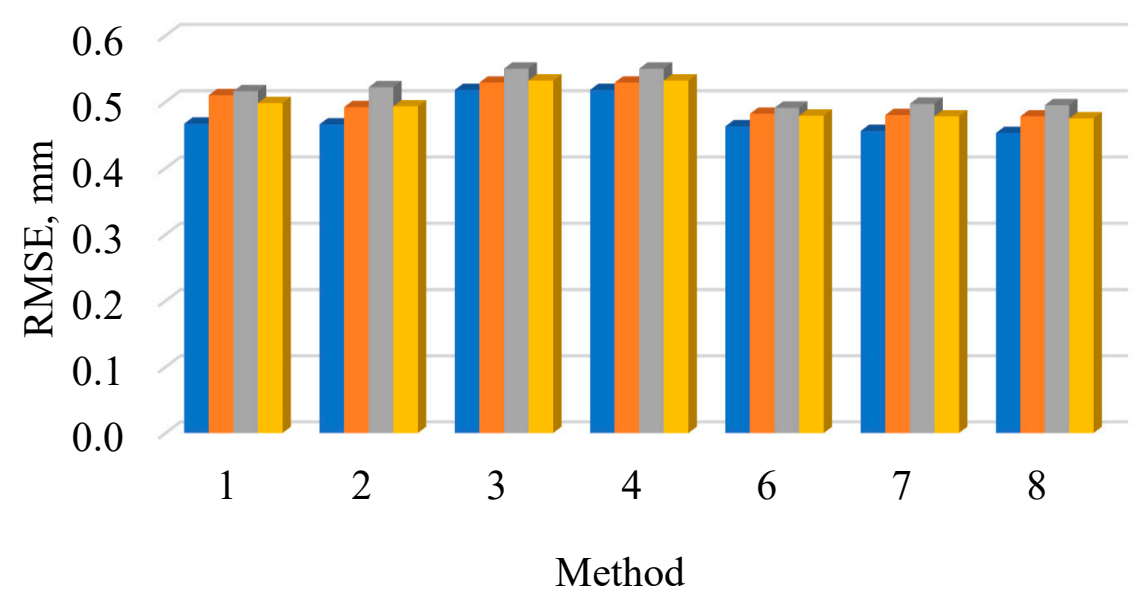

Figure 3. Comparison of different methods for estimating $E T_{0}$, in the x-axis: (1) MARS1, (2) MARS2, (3) M5Tree1, (4) M5Tree2, (5) GMDHNN1, (6) GMDHNN2, (7) CHS, and (8) SS-Adana.

Table 3 reports the training and testing statistics of the employed methods for Antakya Station. Unlike the Adana Station, including the periodicity input considerably improves the accuracy of MARS and M5Tree methods in the testing stage. Similar to for the previous station, here temperature based GMDHNN models also show superior performance to the MARS and M5Tree models in the estimation of $E T_{0}$. All heuristic methods outperform the SS method. A considerable improvement is observed for the HS method after calibration: RMSE and MAE are increased from $1.715 \mathrm{~mm}$ and $1.557 \mathrm{~mm}$ to $0.655 \mathrm{~mm}$ and $0.541 \mathrm{~mm}$ with respect to average statistics, respectively. The SS model has better accuracy than the HS and CHS models in the estimation of $E T_{0}$ using only temperature data as inputs. The relative differences between GMDHNN2 and MARS2/M5Tree/SS models with respect to average RMSE and MAE are 3.7\%/10.7\%/0.8\% and $4 \% / 11.7 \% / 1.1 \%$, respectively. The results of the Antakya Station suggest the use of a periodicity input in model development. The RMSE and NSE values of the applied methods are also compared in Figure 4 for the testing stage. Here the criteria also vary in similar ways for all the methods except for the CHS. Unlike Adana Station, the NSE slightly increases and RMSE decreases from the $50-50 \%$ splitting scenario to a $75-25 \%$ scenario. Comparison of the two stations (compare Figures 3 and 4 or Tables 2 and 3) reveals that the models generally provide better estimates for Antakya Station compared to Adana. A higher correlation between the inputs $\left(T_{\min }\right.$ $T_{\max }, \mathrm{R}_{\mathrm{a}}$ ) and output $\left(E T_{0}\right)$ in Antakya compared to Adana may be the reason for this.

Table 3. RMSE, MAE, and NSE statistics of each model for different data splitting strategies-Antakya.

\begin{tabular}{cccccccc}
\hline \multirow{2}{*}{ Model } & Input & \multicolumn{3}{c}{ Training } & \multicolumn{3}{c}{ Test } \\
\cline { 3 - 8 } & & $\begin{array}{c}\text { RMSE } \\
(\mathbf{m m})\end{array}$ & $\begin{array}{c}\text { MAE } \\
(\mathbf{m m})\end{array}$ & NSE & $\begin{array}{c}\text { RMSE } \\
(\mathbf{m m})\end{array}$ & $\begin{array}{c}\text { MAE } \\
(\mathbf{m m})\end{array}$ & NSE \\
\hline \multicolumn{3}{c}{$\mathbf{5 0 \%}$ training and 50\% test } \\
MARS1 & $T_{\min }, T_{\max }, \mathrm{R}_{\mathrm{a}}$ & 0.383 & 0.290 & 0.959 & 0.635 & 0.521 & 0.872 \\
MARS2 & $T_{\min }, T_{\max }, \mathrm{R}_{\mathrm{a}}, \alpha$ & 0.369 & 0.286 & 0.962 & 0.566 & 0.460 & 0.963 \\
M5Tree1 & $T_{\min }, T_{\max }, \mathrm{R}_{\mathrm{a}}$ & 0.341 & 0.257 & 0.968 & 0.639 & 0.527 & 0.870 \\
M5Tree2 & $T_{\min }, T_{\max }, \mathrm{R}_{\mathrm{a}}, \alpha$ & 0.335 & 0.256 & 0.969 & 0.598 & 0.489 & 0.886 \\
HS & $T_{\min }, T_{\max }, \mathrm{R}_{\mathrm{a}}$ & 1.513 & 1.316 & 0.367 & 1.781 & 1.613 & 0.065 \\
CHS & $T_{\min }, T_{\max }, \mathrm{R}_{\mathrm{a}}$ & 0.641 & 0.456 & 0.886 & 0.718 & 0.603 & 0.848 \\
SS & $T_{\min }, T_{\max }, \mathrm{R}_{\mathrm{a}}$ & 0.438 & 0.339 & 0.947 & 0.678 & 0.572 & 0.864 \\
GMDHNN1 & $T_{\min }, T_{\max }, \mathrm{R}_{\mathrm{a}}$ & 0.350 & 0.268 & 0.963 & 0.552 & 0.436 & 0.912 \\
GMDHNN2 & $T_{\min }, T_{\max }, \mathrm{R}_{\mathrm{a}}, \alpha$ & 0.345 & 0.263 & 0.965 & 0.550 & 0.433 & 0.913 \\
\hline
\end{tabular}


Table 3. Cont.

\begin{tabular}{|c|c|c|c|c|c|c|c|}
\hline \multirow[b]{2}{*}{ Model } & \multirow[b]{2}{*}{ Input } & \multicolumn{3}{|c|}{ Training } & \multicolumn{3}{|c|}{ Test } \\
\hline & & $\begin{array}{c}\text { RMSE } \\
\text { (mm) }\end{array}$ & $\begin{array}{l}\text { MAE } \\
(\mathrm{mm})\end{array}$ & NSE & $\begin{array}{c}\text { RMSE } \\
(\mathrm{mm})\end{array}$ & $\begin{array}{l}\text { MAE } \\
(\mathrm{mm})\end{array}$ & NSE \\
\hline \multicolumn{8}{|c|}{$60 \%$ training and $40 \%$ test } \\
\hline MARS1 & $T_{\min }, T_{\max }, \mathrm{R}_{\mathrm{a}}$ & 0.464 & 0.359 & 0.938 & 0.468 & 0.370 & 0.933 \\
\hline MARS2 & $T_{\min }, T_{\max }, R_{a}, \alpha$ & 0.454 & 0.345 & 0.941 & 0.453 & 0.373 & 0.966 \\
\hline M5Tree1 & $T_{\min }, T_{\max }, R_{a}$ & 0.406 & 0.305 & 0.953 & 0.478 & 0.380 & 0.930 \\
\hline M5Tree2 & $T_{\min }, T_{\max }, \mathrm{R}_{\mathrm{a}}, \alpha$ & 0.439 & 0.326 & 0.945 & 0.441 & 0.348 & 0.941 \\
\hline HS & $T_{\min }, T_{\max }, R_{\mathrm{a}}$ & 1.612 & 1.402 & 0.256 & 1.722 & 1.569 & 0.127 \\
\hline CHS & $T_{\min }, T_{\max }, \mathrm{R}_{\mathrm{a}}$ & 0.676 & 0.487 & 0.869 & 0.647 & 0.538 & 0.877 \\
\hline SS & $T_{\min }, T_{\max }, \mathrm{R}_{\mathrm{a}}$ & 0.526 & 0.400 & 0.921 & 0.510 & 0.436 & 0.923 \\
\hline GMDHNN1 & $T_{\min }, T_{\max }, \mathrm{R}_{\mathrm{a}}$ & 0.441 & 0.339 & 0.939 & 0.426 & 0.345 & 0.943 \\
\hline GMDHNN2 & $T_{\min }, T_{\max }, \mathrm{R}_{\mathrm{a}}, \alpha$ & 0.430 & 0.335 & 0.941 & 0.424 & 0.342 & 0.945 \\
\hline \multicolumn{8}{|c|}{$75 \%$ training and $25 \%$ test } \\
\hline MARS1 & $T_{\min }, T_{\max }, \mathrm{R}_{\mathrm{a}}$ & 0.455 & 0.351 & 0.941 & 0.368 & 0.276 & 0.957 \\
\hline MARS2 & $T_{\min }, T_{\max }, \mathrm{R}_{\mathrm{a}}, \alpha$ & 0.443 & 0.349 & 0.944 & 0.335 & 0.269 & 0.971 \\
\hline M5Tree1 & $T_{\min }, T_{\max }, \mathrm{R}_{\mathrm{a}}$ & 0.390 & 0.291 & 0.957 & 0.373 & 0.304 & 0.963 \\
\hline M5Tree2 & $T_{\min }, T_{\max }, \mathrm{R}_{\mathrm{a}}, \alpha$ & 0.406 & 0.299 & 0.953 & 0.367 & 0.292 & 0.958 \\
\hline HS & $T_{\min }, T_{\max }, \mathrm{R}_{\mathrm{a}}$ & 1.663 & 1.463 & 0.211 & 1.641 & 1.489 & 0.168 \\
\hline CHS & $T_{\min }, T_{\max }, \mathrm{R}_{\mathrm{a}}$ & 0.677 & 0.497 & 0.869 & 0.601 & 0.481 & 0.888 \\
\hline SS & $T_{\min }, T_{\max }, \mathrm{R}_{\mathrm{a}}$ & 0.526 & 0.416 & 0.621 & 0.410 & 0.327 & 0.648 \\
\hline GMDHNN1 & $T_{\min }, T_{\max }, \mathrm{R}_{\mathrm{a}}$ & 0.439 & 0.347 & 0.940 & 0.318 & 0.248 & 0.968 \\
\hline GMDHNN2 & $T_{\min }, T_{\max }, R_{a}, \alpha$ & 0.426 & 0.337 & 0.944 & 0.304 & 0.247 & 0.969 \\
\hline \multicolumn{8}{|c|}{ Average } \\
\hline MARS1 & $T_{\min }, T_{\max }, \mathrm{R}_{\mathrm{a}}$ & 0.434 & 0.333 & 0.946 & 0.490 & 0.389 & 0.921 \\
\hline MARS2 & $T_{\min }, T_{\max }, R_{a}, \alpha$ & 0.422 & 0.327 & 0.949 & 0.451 & 0.367 & 0.967 \\
\hline M5Tree1 & $T_{\min }, T_{\max }, \mathrm{R}_{\mathrm{a}}$ & 0.379 & 0.284 & 0.959 & 0.497 & 0.404 & 0.921 \\
\hline M5Tree2 & $T_{\min }, T_{\max }, \mathrm{R}_{\mathrm{a}}, \alpha$ & 0.393 & 0.294 & 0.956 & 0.469 & 0.376 & 0.928 \\
\hline HS & $T_{\min }, T_{\max }, \mathrm{R}_{\mathrm{a}}$ & 1.596 & 1.394 & 0.278 & 1.715 & 1.557 & 0.120 \\
\hline CHS & $T_{\min }, T_{\max }, \mathrm{R}_{\mathrm{a}}$ & 0.665 & 0.480 & 0.875 & 0.655 & 0.541 & 0.871 \\
\hline SS & $T_{\min }, T_{\max }, \mathrm{R}_{\mathrm{a}}$ & 0.497 & 0.385 & 0.830 & 0.533 & 0.445 & 0.812 \\
\hline GMDHNN1 & $T_{\min }, T_{\max }, \mathrm{R}_{\mathrm{a}}$ & 0.410 & 0.318 & 0.947 & 0.432 & 0.343 & 0.941 \\
\hline GMDHNN2 & $T_{\min }, T_{\max }, \mathrm{R}_{\mathrm{a}}, \alpha$ & 0.401 & 0.312 & 0.950 & 0.426 & 0.341 & 0.942 \\
\hline
\end{tabular}

$T_{\min }, T_{\max }, \mathrm{R}_{\mathrm{a}}$ and $\alpha$ are minimum and maximum temperatures, extraterrestrial radiation, and periodicity (month number), respectively. RMSE, MAE, and NSE are the root mean square error, mean absolute error, and efficiency coefficient, respectively.

$$
\square 50 \%-50 \% \quad \square 0 \%-40 \% \quad \square 75 \%-25 \% \quad \square \text { Average }
$$

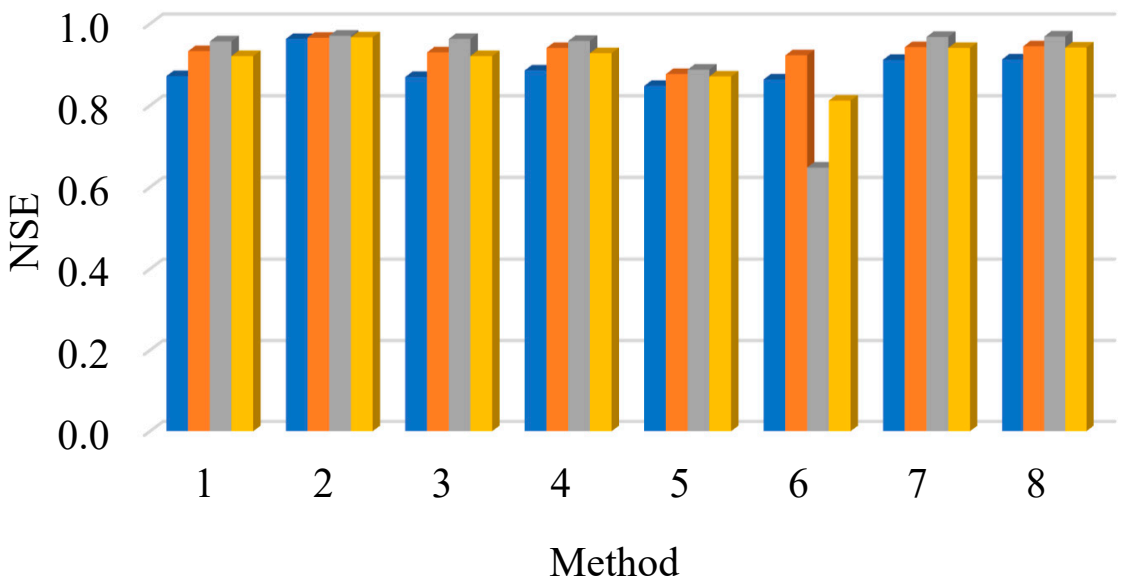

Figure 4. Cont. 


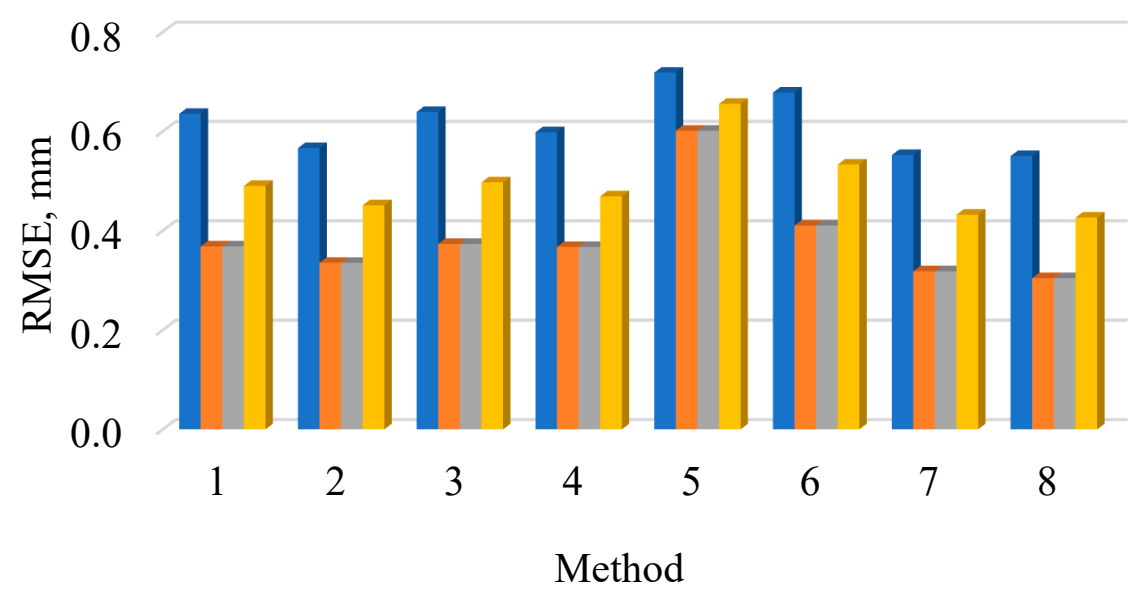

Figure 4. Comparison of different methods for estimating $E T_{0}$, in the x-axis: (1) MARS1, (2) MARS2, (3) M5Tree1, (4) M5Tree2, (5) GMDHNN1, (6) GMDHNN2, (7) CHS and (8) SS-Antakya.

Figure 5 illustrates the FAO-56 PM and estimated $E T_{0}$ obtained by using six different methods for Adana Station. It is apparent from the scatterplots that the HS considerably overestimates $E T_{0}$ while the CHS has less scattered estimates compared to HS. GMDHNN and SS methods have the least scattered estimates among the applied methods and are closely followed by the MARS method. The methods are graphically compared in Figure 6 in estimation of $E T_{0}$ of Antakya Station. Here the CHS also considerably improves the HS accuracy. GMDHNN also has the least scattered estimates followed by the MARS in this station.
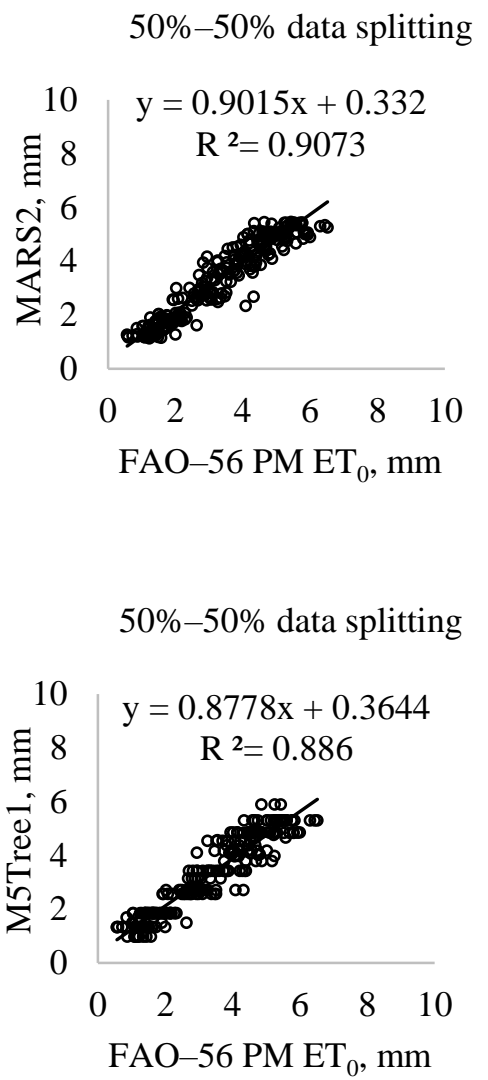

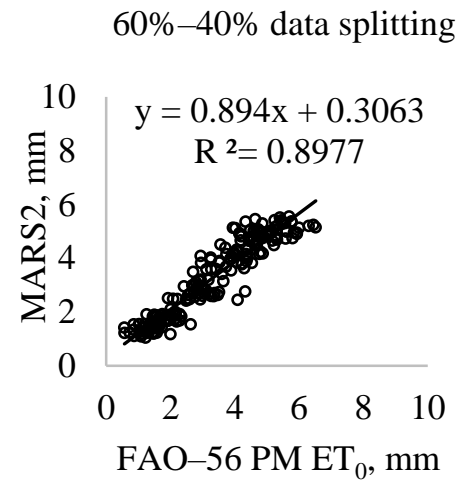

(a)

$60 \%-40 \%$ data splitting

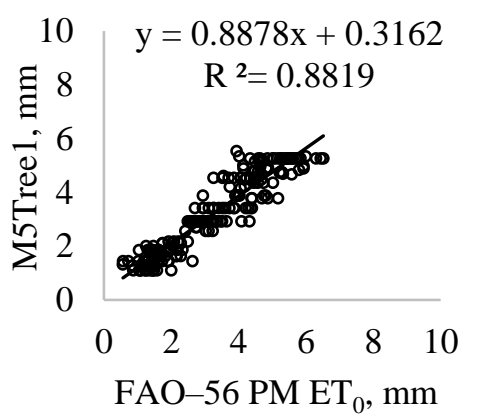

(b)
$75 \%-25 \%$ data splitting

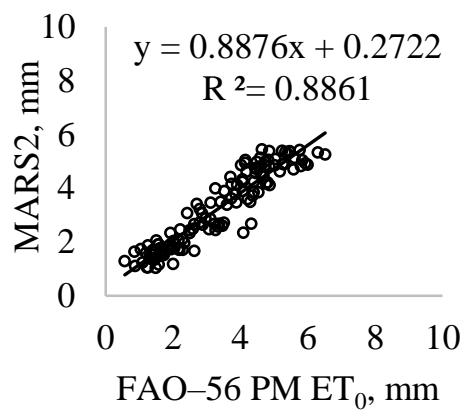

75\%-25\% data splitting

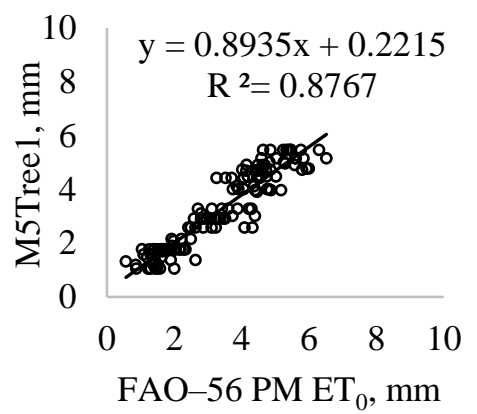

Figure 5. Cont. 
$50 \%-50 \%$ data splitting

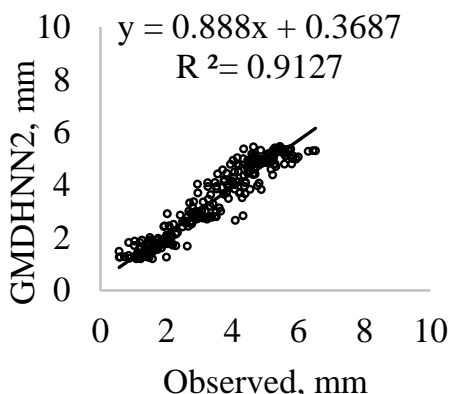

Observed, mm

$50 \%-50 \%$ data splitting $y=1.3646 x+0.5765$

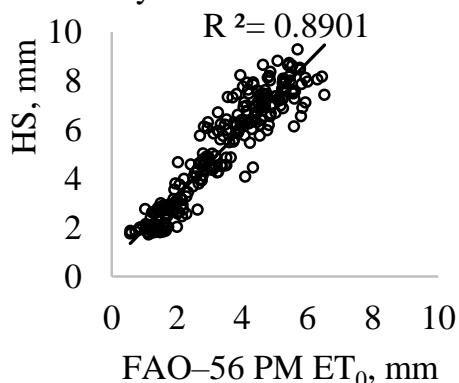

50\%-50\% data splitting

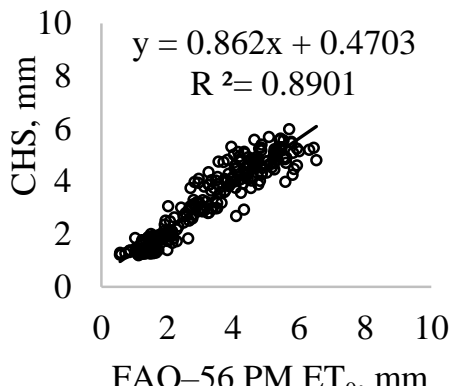

FAO-56 PM ET, mm

50\%-50\% data splitting

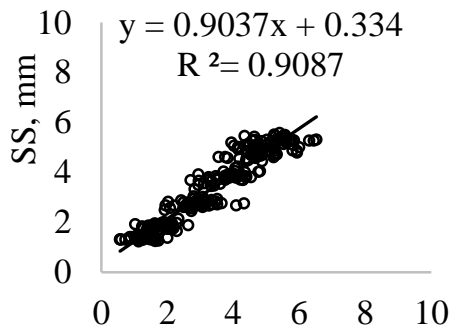

FAO-56 PM ET, mm
$60 \%-40 \%$ data splitting

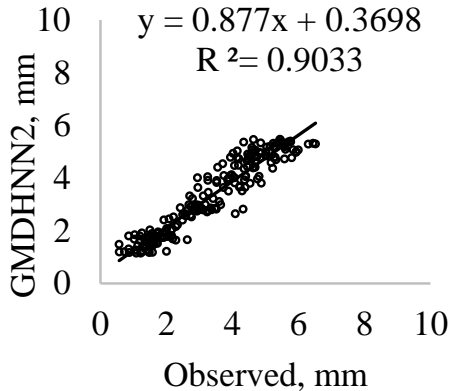

(c)

$60 \%-40 \%$ data splitting

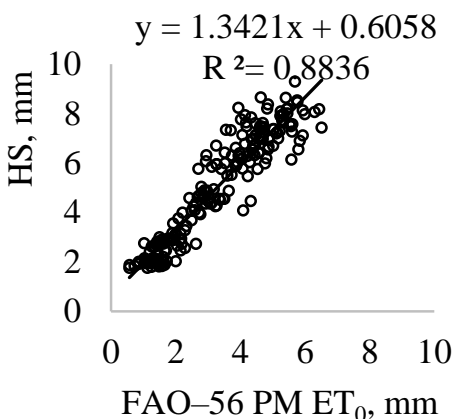

(d)

$60 \%-40 \%$ data splitting

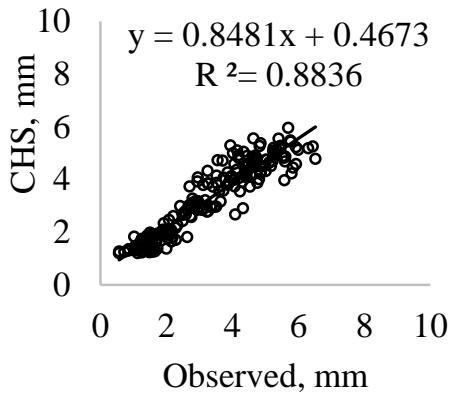

(e)

$60 \%-40 \%$ data splitting



FAO-56 PM ET ${ }_{0}$, mm

(f)
$75 \%-25 \%$ data splitting

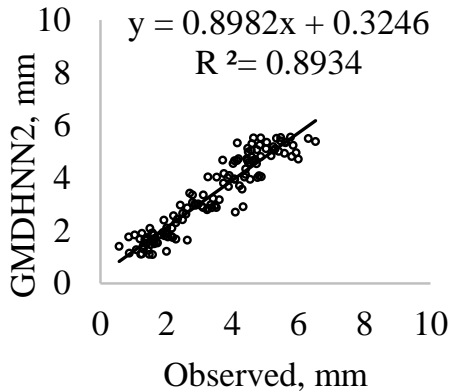

$75 \%-25 \%$ data splitting

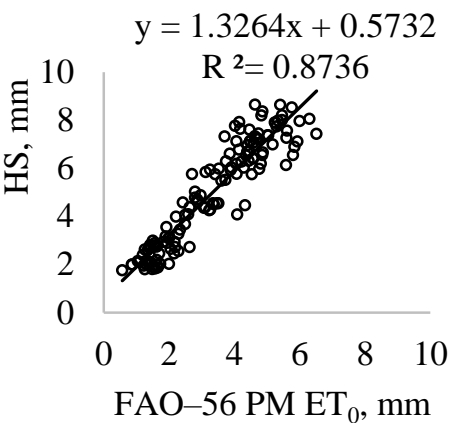

$75 \%-25 \%$ data splitting

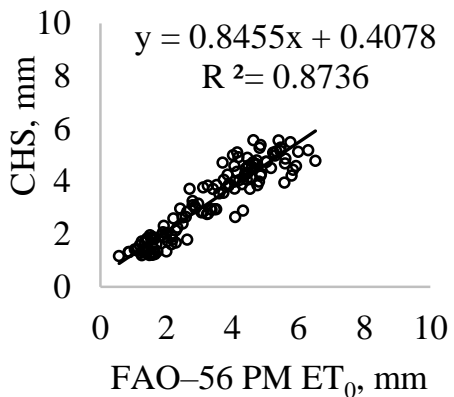

$75 \%-25 \%$ data splitting

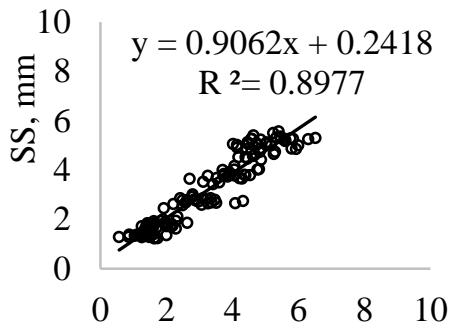

FAO-56 PM ET ${ }_{0}$, mm

Figure 5. The FAO-56 PM and estimated ET 0 by: (a) MARS, (b) M5tree, (c) GMDHNN, (d) HS, (e) CHS, and (f) SS methods-Adana. 


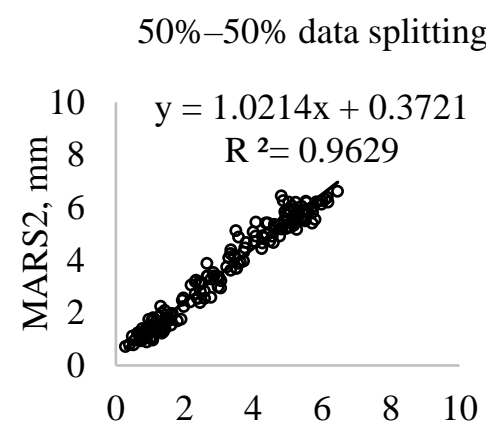

FAO-56 $\mathrm{PM} \mathrm{ET}_{0}$, mm

50\%-50\% data splitting

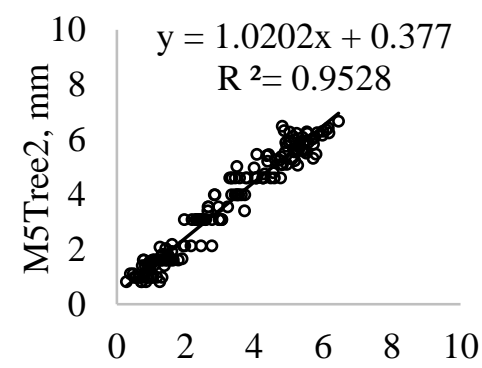

FAO-56 $\mathrm{PM} \mathrm{ET}_{0}, \mathrm{~mm}$

50\%-50\% data splitting
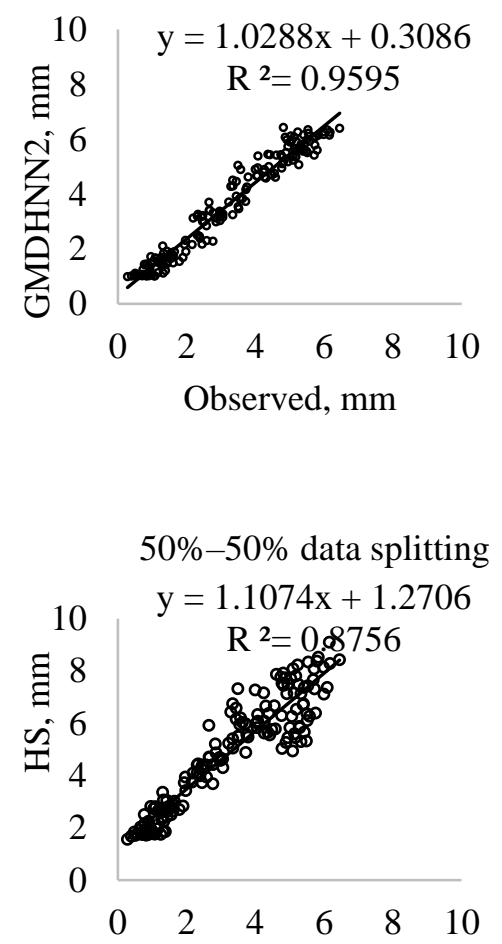

FAO-56 $\mathrm{PM} \mathrm{ET}_{0}, \mathrm{~mm}$
60\%-40\% data splitting

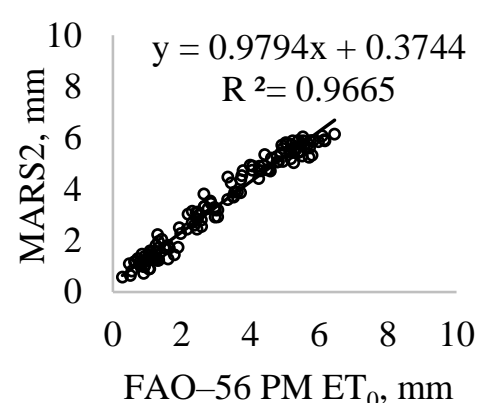

(a)

$60 \%-40 \%$ data splitting

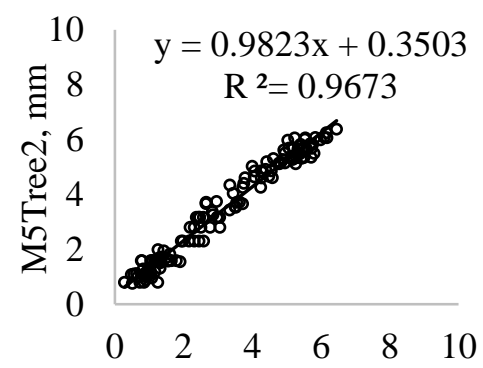

FAO-56 PM ET 0 , mm

(b)

60\%-40\% data splitting

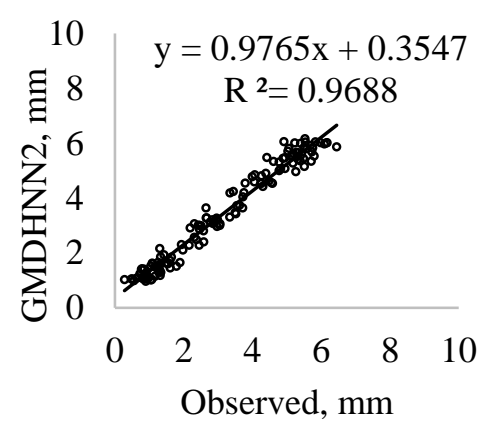

(c)

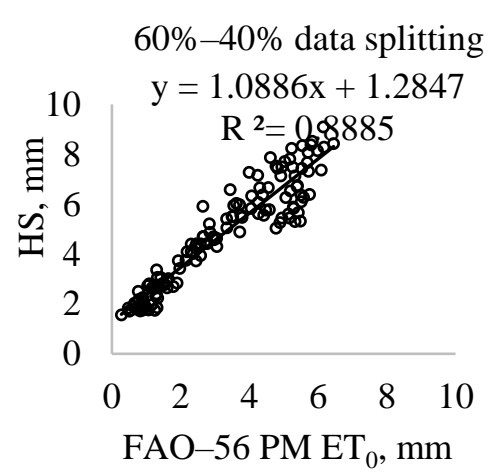

(d)
$75 \%-25 \%$ data splitting

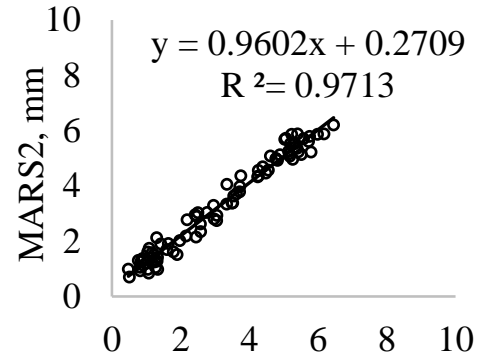

FAO-56 $\mathrm{PM} \mathrm{ET}_{0}$, mm

$75 \%-25 \%$ data splitting

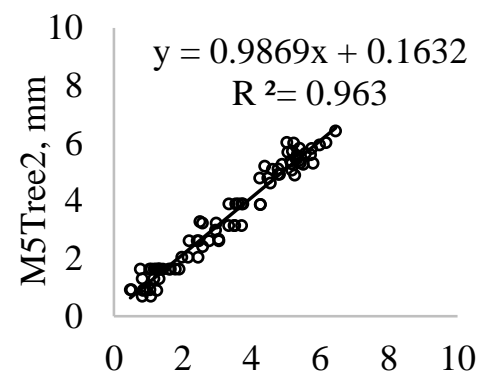

FAO-56 $\mathrm{PM} \mathrm{ET}_{0}$, mm

$75 \%-25 \%$ data splitting
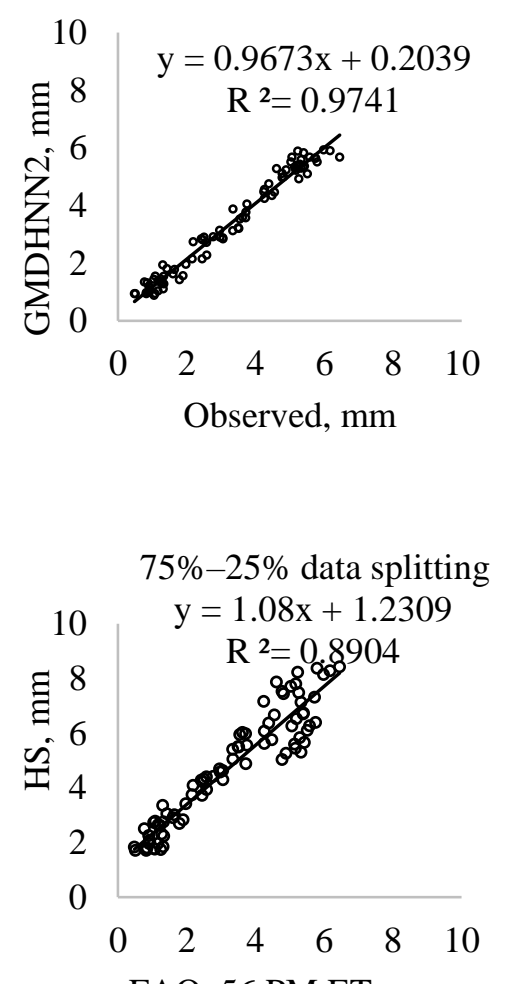

FAO-56 $\mathrm{PM} \mathrm{ET}_{0}, \mathrm{~mm}$

Figure 6. Cont. 


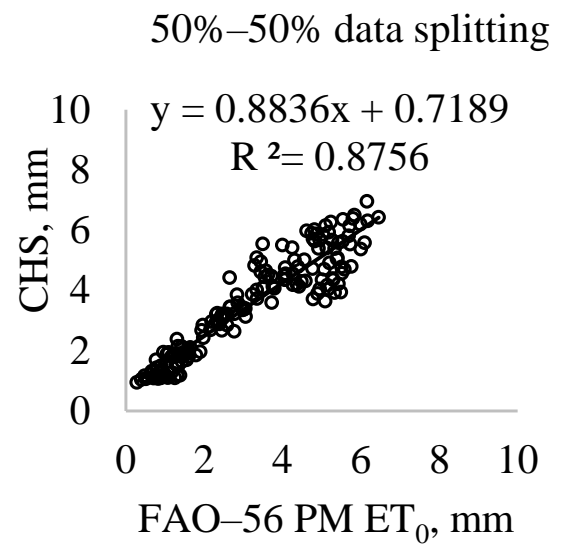

$50 \%-50 \%$ data splitting

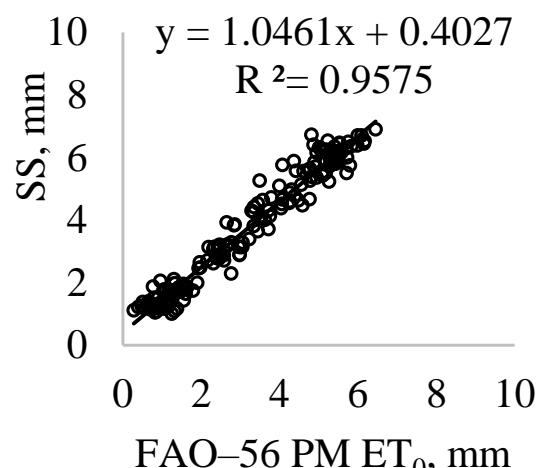

$60 \%-40 \%$ data splitting

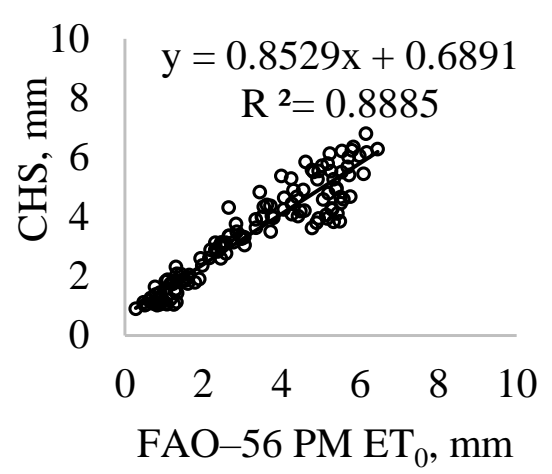

(e)

$60 \%-40 \%$ data splitting

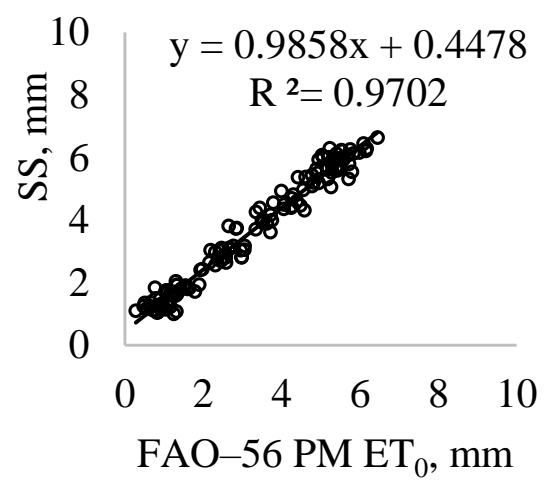

$75 \%-25 \%$ data splitting

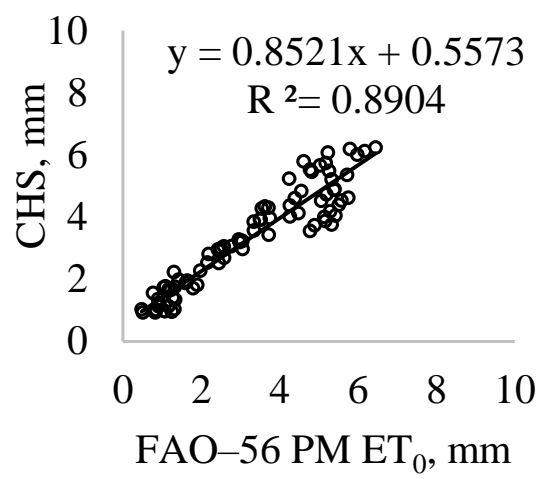

$75 \%-25 \%$ data splitting

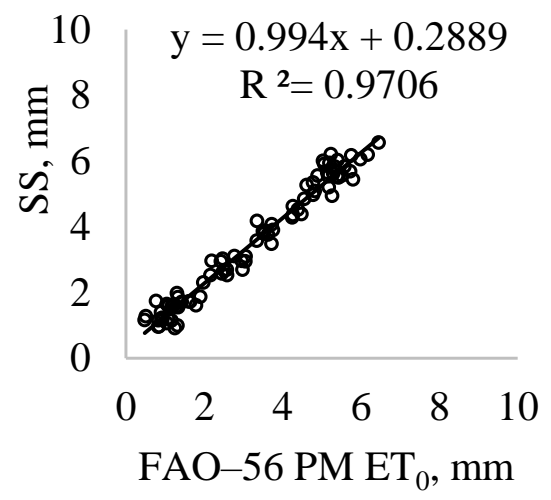

(f)

Figure 6. The FAO-56 PM and estimated ET 0 obtained by: (a) MARS, (b) M5tree, (c) GMDHNN, (d) HS, (e) CHS, and (f) SS methods-Antakya.

The monthly mean estimates of the GMDHNN, MARS, M5Tree, HS, CHS, and SS methods are compared in Figure 7. In Adana Station, the GMDHNN2, MARS2, M5Tree1, and SS model results are generally very close to each other while the CHS underestimates the $E T_{0}$ of March and May and overestimates those of July and August. The models' estimates do not considerably change with respect to splitting scenarios. In Antakya Station, however, the models' accuracy changes for different train-test scenarios. For example, the GMDHNN2, MARS2, M5Tree1, and SS models are less successful in estimation of $E T_{0}$ in the case of the $50-50 \%$ splitting scenario while the $75-25 \%$ train-test scenario provides the best estimates. This also confirms the necessity of considering different splitting scenarios in evaluating the accuracy of the applied methods in the estimation of $E T_{0}$. It is apparent that the CHS has the worst estimates while the GMDHNN2 maps the mean monthly $E T_{0}$ better than the other models. All the models underestimate $E T_{0}$ of Antakya Station in the $50-50 \%$ splitting scenario. 

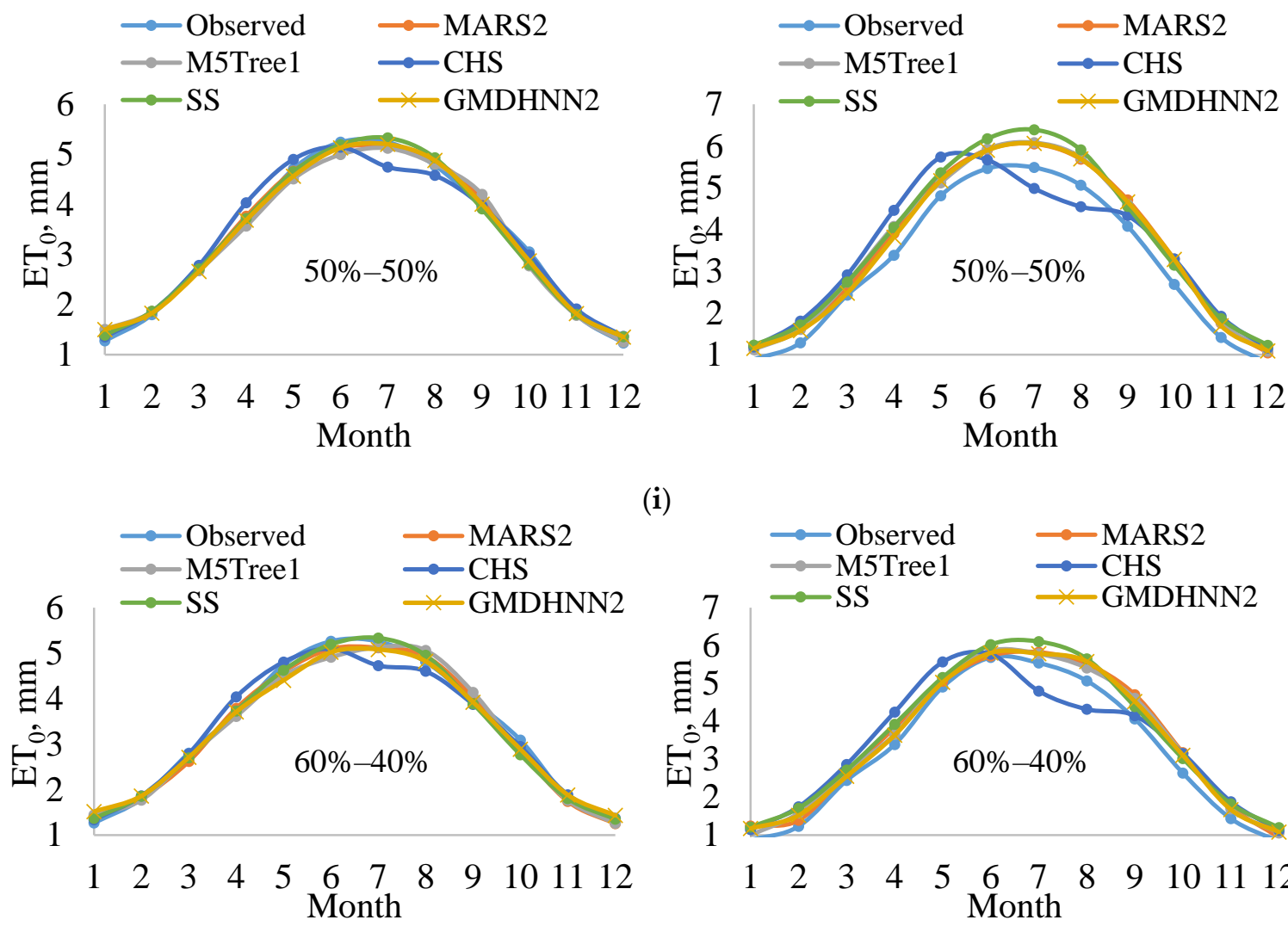

(i)

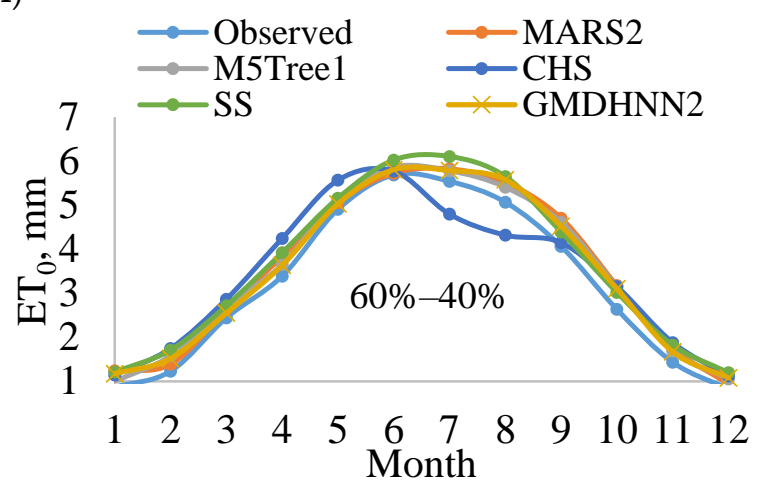

(ii)

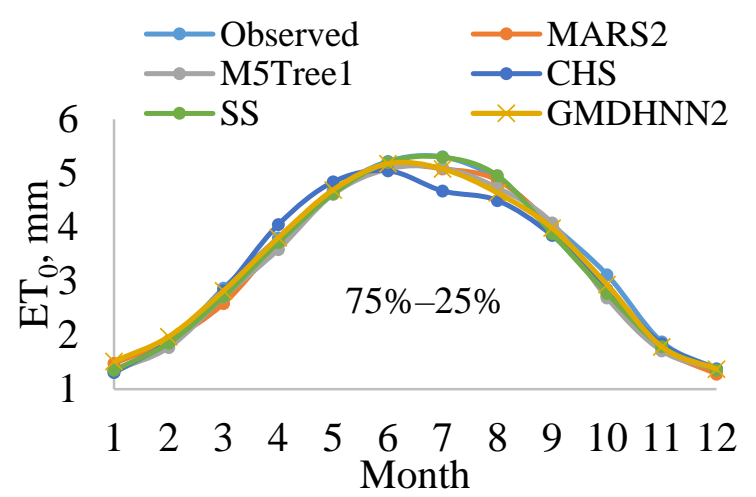

(iii)

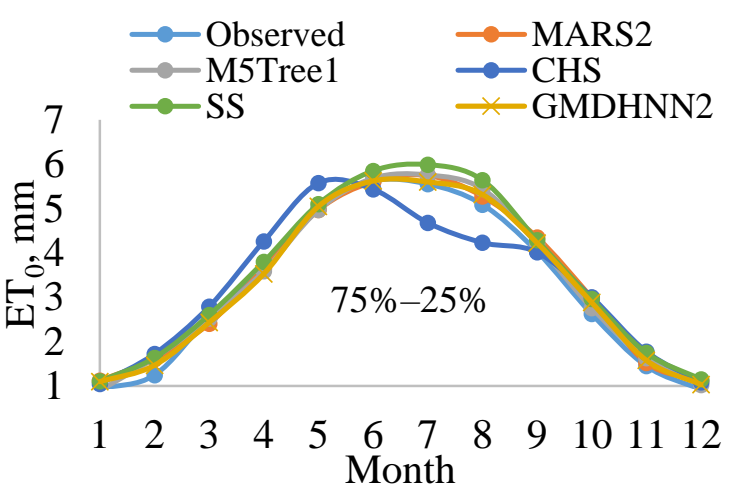

(b)

Figure 7. The FAO-56 PM and estimated monthly mean $E T_{0}$ by MARS, M5tree, GMDHNN, CHS and SS methods: (a) Adana, (b) Antakya using different splitting scenarios: (i) 50-50\% (ii), 60-40\%, (iii) $75-25 \%$.

\section{Conclusions}

The ability of new temperature based regression methods were compared with Hargreaves-Samani, calibrated Hargreaves-Samani, and Stephens-Stewart methods in modeling monthly reference evapotranspiration. The applied models only used maximum and minimum temperatures and extraterrestrial radiation inputs that were measured and calculated for two stations in Turkey. Data division scenarios of $50-50 \%, 60-40 \%$, and $75-25 \%$ were applied in the study to evaluate the aforementioned methods. The periodicity component (the month number of the year varying from 1 January to 12 December) was also used as an input to the models so as to examine its effect on models' performances. 
Three commonly used criteria: RMSE, MAE, and NSE, were used for comparison of the methods. The results indicated the following conclusions:

In Adana Station, GMDHNN and the SS model performed better than the other models. In Antakya Station, however, the GMDHNN model provided the best accuracy followed by the MARS and M5Tree in modeling monthly reference evapotranspiration.

The calibration procedure considerably increased HS model accuracy. For example, average RMSE and MAE statistics of HS were increased from $1.715 \mathrm{~mm}$ and $1.557 \mathrm{~mm}$ to $0.655 \mathrm{~mm}$ and $0.541 \mathrm{~mm}$ for Antakya Station.

The periodicity component increased the accuracy of GMDHNN, MARS, and M5Tree models in Antakya Station only. RMSE decrements of the GMDHNN, MARS, and M5Tree models in the test stage were $1.4 \%, 8 \%$, and $6 \%$, respectively.

The applications revealed the necessity of using different data division scenarios for better evaluation of the compared models.

Comparison of the models in estimating monthly mean reference evapotranspiration revealed that the GMDHNN model generally had better accuracy compared to other models while the CHS models provided the worst estimates. By implementing the GMDHNN model, the average RMSE of MARS, M5Tree, HS, CHS, and SS models respectively decreased by $3.7-6.4 \%, 10.7-3.9 \%, 76-75 \%, 10-35 \%$, and $0.8-17 \%$ when estimating monthly $E T_{0}$.

The results of this study recommend the use of the GMDHNN model for the prediction of $E T_{0}$ in regions where only the temperature is available while other meteorological data are not available or are missing for a long duration.

Author Contributions: Conceptualization: R.M.A., O.K. and Z.M.Y. Formal analysis: S.H., Z.M.Y., S.S., O.K. and B.L. Validation: R.M.A., S.H., Z.M.Y., S.S., O.K. and B.L. Supervision: S.S. and O.K. Writing original draft: R.M.A., S.H., Z.M.Y., S.S., O.K. and B.L. Visualization: R.M.A., S.H. and Z.M.Y. investigation: R.M.A., S.H. and Z.M.Y. All authors have read and agreed to the published version of the manuscript.

Funding: This research was supported by the National Key R\&D Program of China. (2016YFC0402706). Institutional Review Board Statement: Not applicable.

Informed Consent Statement: Not applicable.

Data Availability Statement: The data presented in this study will be available on interested request from the corresponding author.

Conflicts of Interest: There is no conflict of interest in this study.

\section{References}

1. Jing, W.; Yaseen, Z.M.; Shahid, S.; Saggi, M.K.; Tao, H.; Kisi, O.; Salih, S.Q.; Al-Ansari, N.; Chau, K.W. Implementation of evolutionary computing models for reference evapotranspiration modeling: Short review, assessment and possible future research directions. Eng. Appl. Comput. Fluid Mech. 2019, 13, 811-823. [CrossRef]

2. Allen, R.G.; Pereira, L.S.; Howell, T.A.; Jensen, M.E. Evapotranspiration information reporting: I. Factors governing measurement accuracy. Agric. Water Manag. 2011, 98, 899-920. [CrossRef]

3. Allen, R.G.; Pereira, L.S.; Howell, T.A.; Jensen, M.E. Evapotranspiration information reporting: II. Recommended documentation. Agric. Water Manag. 2011, 98, 921-929. [CrossRef]

4. Ren, X.; Qu, Z.; Martins, D.S.; Paredes, P.; Pereira, L.S. Daily reference evapotranspiration for hyper-arid to moist sub-humid climates in inner mongolia, China: I. Assessing temperature methods and spatial variability. Water Resour. Manag. 2016, 30, 3769-3791. [CrossRef]

5. Xing, W.; Wang, W.; Shao, Q.; Peng, S.; Yu, Z.; Yong, B.; Taylor, J. Changes of reference evapotranspiration in the Haihe River Basin: Present observations and future projection from climatic variables through multi-model ensemble. Glob. Planet. Chang. 2014, 115, 1-15. [CrossRef]

6. Valiantzas, J.D. Temperature-and humidity-based simplified Penman's ET0 formulae. Comparisons with temperature-based Hargreaves-Samani and other methodologies. Agric. Water Manag. 2018, 208, 326-334. [CrossRef]

7. Allen, R.G.; Pereira, L.S.; Raes, D.; Smith, M. Crop evapotranspiration-Guidelines for computing crop water requirements-FAO Irrigation and drainage paper 56. FAO Rome 1998, 300, D05109. 
8. Yaseen, Z.M.; Sulaiman, S.O.; Deo, R.C.; Chau, K.-W. An enhanced extreme learning machine model for river flow forecasting: State-of-the-art, practical applications in water resource engineering area and future research direction. J. Hydrol. 2018, 569, 387-408. [CrossRef]

9. Khosravinia, P.; Nikpour, M.R.; Kisi, O.; Yaseen, Z.M. Application of novel data mining algorithms in prediction of discharge and end depth in trapezoidal sections. Comput. Electron. Agric. 2020, 170, 105283. [CrossRef]

10. Zhu, S.; Ptak, M.; Yaseen, Z.M.; Dai, J.; Sivakumar, B. Forecasting surface water temperature in lakes: A comparison of approaches. J. Hydrol. 2020, 585, 124809. [CrossRef]

11. Yuan, X.; Chen, C.; Lei, X.; Yuan, Y.; Adnan, R.M. Monthly runoff forecasting based on LSTM-ALO model. Stoch. Environ. Res. Risk Assess. 2018, 32, 2199-2212. [CrossRef]

12. Adnan, R.M.; Liang, Z.; Yuan, X.; Kisi, O.; Akhlaq, M.; Li, B. Comparison of LSSVR, M5RT, NF-GP, and NF-SC models for predictions of hourly wind speed and wind power based on cross-validation. Energies 2019, 12, 329. [CrossRef]

13. Kisi, O.; Shiri, J.; Karimi, S.; Adnan, R.M. Three different adaptive neuro fuzzy computing techniques for forecasting long-period daily streamflows. In Big Data in Engineering Applications; Springer: Singapore, 2018; pp. 303-321.

14. Alizamir, M.; Kisi, O.; Muhammad Adnan, R.; Kuriqi, A. Modelling reference evapotranspiration by combining neuro-fuzzy and evolutionary strategies. Acta Geophys. 2020, 68, 1113-1126. [CrossRef]

15. Petković, B.; Petković, D.; Kuzman, B.; Milovančević, M.; Wakil, K.; Ho, L.S.; Jermsittiparsert, K. Neuro-fuzzy estimation of reference crop evapotranspiration by neuro fuzzy logic based on weather conditions. Comput. Electron. Agric. 2020, 173, 105358. [CrossRef]

16. Zhu, B.; Feng, Y.; Gong, D.; Jiang, S.; Zhao, L.; Cui, N. Hybrid particle swarm optimization with extreme learning machine for daily reference evapotranspiration prediction from limited climatic data. Comput. Electron. Agric. 2020, 173, 105430. [CrossRef]

17. Jovic, S.; Nedeljkovic, B.; Golubovic, Z.; Kostic, N. Evolutionary algorithm for reference evapotranspiration analysis. Comput. Electron. Agric. 2018, 150,1-4. [CrossRef]

18. Adnan, R.M.; Chen, Z.; Yuan, X.; Kisi, O.; El-Shafie, A.; Kuriqi, A.; Ikram, M. Reference Evapotranspiration Modeling Using New Heuristic Methods. Entropy 2020, 22, 547. [CrossRef]

19. Khoshravesh, M.; Sefidkouhi, M.A.G.; Valipour, M. Estimation of reference evapotranspiration using multivariate fractional polynomial, Bayesian regression, and robust regression models in three arid environments. Appl. Water Sci. 2015, 7, 1911-1922. [CrossRef]

20. Mattar, M.A. Using gene expression programming in monthly reference evapotranspiration modeling: A case study in Egypt. Agric. Water Manag. 2018, 198, 28-38. [CrossRef]

21. Mehdizadeh, S. Estimation of daily reference evapotranspiration (ETo) using artificial intelligence methods: Offering a new approach for lagged ETo data-based modeling. J. Hydrol. 2018, 559, 794-812. [CrossRef]

22. Mehdizadeh, S.; Behmanesh, J.; Khalili, K. Comprehensive modeling of monthly mean soil temperature using multivariate adaptive regression splines and support vector machine. Theor. Appl. Climatol. 2017, 133, 911-924. [CrossRef]

23. Sanikhani, H.; Kisi, O.; Maroufpoor, E.; Yaseen, Z.M. Temperature-based modeling of reference evapotranspiration using several artificial intelligence models: Application of different modeling scenarios. Theor. Appl. Climatol. 2018. [CrossRef]

24. Shiri, J. Improving the performance of the mass transfer-based reference evapotranspiration estimation approaches through a coupled wavelet-random forest methodology. J. Hydrol. 2018, 561, 737-750. [CrossRef]

25. Tao, H.; Diop, L.; Bodian, A.; Djaman, K.; Ndiaye, P.M.; Yaseen, Z.M. Reference evapotranspiration prediction using hybridized fuzzy model with firefly algorithm: Regional case study in Burkina Faso. Agric. Water Manag. 2018, 208, 140-151. [CrossRef]

26. Yin, Z.; Wen, X.; Feng, Q.; He, Z.; Zou, S.; Yang, L. Integrating genetic algorithm and support vector machine for modeling daily reference evapotranspiration in a semi-arid mountain area. Hydrol. Res. 2016, 48, 1177-1191. [CrossRef]

27. Adamala, S. Temperature based generalized wavelet-neural network models to estimate evapotranspiration in India. Inf. Process. Agric. 2018, 5, 149-155. [CrossRef]

28. Gavili, S.; Sanikhani, H.; Kisi, O.; Mahmoudi, M.H. Evaluation of several soft computing methods in monthly evapotranspiration modelling. Meteorol. Appl. 2017, 25, 128-138. [CrossRef]

29. Karbasi, M. Forecasting of multi-step ahead reference evapotranspiration using wavelet- gaussian process regression model. Water Resour. Manag. 2017, 32, 1035-1052. [CrossRef]

30. Farlow, S.J. The GMDH algorithm of Ivakhnenko. Am. Stat. 1981, 35, 210-215.

31. Adnan, R.M.; Khosravinia, P.; Karimi, B.; Kisi, O. Prediction of hydraulics performance in drain envelopes using Kmeans based multivariate adaptive regression spline. Appl. Soft Comput. 2020, 100, 107008. [CrossRef]

32. Nasir, V.; Nourian, S.; Avramidis, S.; Cool, J. Prediction of physical and mechanical properties of thermally modified wood based on color change evaluated by means of "group method of data handling"(GMDH) neural network. Holzforschung 2019, 73, 381-392. [CrossRef]

33. Adnan, R.M.; Liang, Z.; Parmar, K.S.; Soni, K.; Kisi, O. Modeling monthly streamflow in mountainous basin by MARS, GMDH-NN and DENFIS using hydroclimatic data. Neural Comput. Appl. 2020. [CrossRef]

34. Nkurlu, B.M.; Shen, C.; Asante-Okyere, S.; Mulashani, A.K.; Chungu, J.; Wang, L. Prediction of permeability using group method of data handling (GMDH) neural network from well log data. Energies 2020, 13, 551. [CrossRef]

35. Najafzadeh, M.; Barani, G.-A.; Kermani, M.R.H. Estimation of pipeline scour due to waves by GMDH. J. Pipeline Syst. Eng. Pract. 2014, 5, 06014002. [CrossRef] 
36. Najafzadeh, M.; Barani, G.-A.; Hessami-Kermani, M.-R. Evaluation of GMDH networks for prediction of local scour depth at bridge abutments in coarse sediments with thinly armored beds. Ocean Eng. 2015, 104, 387-396. [CrossRef]

37. Najafzadeh, M.; Zahiri, A. Neuro-fuzzy GMDH-based evolutionary algorithms to predict flow discharge in straight compound channels. J. Hydrol. Eng. 2015, 20, 4015035. [CrossRef]

38. Shahabi, S.; Khanjani, M.-J.; Kermani, M.H. Hybrid wavelet-GMDH model to forecast significant wave height. Water Supply 2015, 16, 453-459. [CrossRef]

39. Tsai, T.-M.; Yen, P.-H. GMDH algorithms applied to turbidity forecasting. Appl. Water Sci. 2016, 7, 1151-1160. [CrossRef]

40. Parsaie, A.; Haghiabi, A.H. Improving modelling of discharge coefficient of triangular labyrinth lateral weirs using SVM, GMDH and MARS techniques. Irrig. Drain. 2017, 66, 636-654. [CrossRef]

41. Alitaleshi, F.; Daghbandan, A. Using a multi-objective optimal design of GMDH type neural networks to evaluate the quality of treated water in a water treatment plant. Desalination Water Treat. 2019, 139, 123-132. [CrossRef]

42. Daghbandan, A.; Khalatbari, S.; Abbasi, M.M. Applying GMDH-type neural network for modeling and prediction of turbidity and free residual aluminium in drinking water. Desalination Water Treat. 2019, 140, 118-131. [CrossRef]

43. Da Silva Carvalho, R.L.; Delgado, A.R.S. Estimativas da evapotranspiração de referência do município de Ariquemes (RO) utilizando os métodos Penman-Monteith-FAO e Hargreaves-Samani. Rev. Bras. De Agric. Irrig. 2016, 10, $1038-1048$.

44. Friedman, J.H. Multivariate adaptive regression splines. Ann. Stat. 1991, 19, 1-67. [CrossRef]

45. Quinlan, J.R. Learning with Continuous Classes. In Proceedings of the 5th Australian Joint Conference on Artificial Intelligence, Hobart, Tasmania, 16-18 November 1992; pp. 343-348.

46. Adnan, R.M.; Liang, Z.; Trajkovic, S.; Zounemat-Kermani, M.; Li, B.; Kisi, O. Daily streamflow prediction using optimally pruned extreme learning machine. J. Hydrol. 2019, 577, 123981. [CrossRef]

47. Kisi, O.; Parmar, K.S. Application of least square support vector machine and multivariate adaptive regression spline models in long term prediction of river water pollution. J. Hydrol. 2016. [CrossRef]

48. Adnan, R.M.; Liang, Z.; El-Shafie, A.; Zounemat-Kermani, M.; Kisi, O. Prediction of suspended sediment load using data-driven models. Water 2019, 11, 2060. [CrossRef]

49. Yin, Z.; Feng, Q.; Wen, X.; Deo, R.C.; Yang, L.; Si, J.; He, Z. Design and evaluation of SVR, MARS and M5Tree models for 1, 2 and 3-day lead time forecasting of river flow data in a semiarid mountainous catchment. Stoch. Environ. Res. Risk Assess. 2018, 32, 2457-2476. [CrossRef]

50. Ghaemi, A.; Rezaie-Balf, M.; Adamowski, J.; Kisi, O.; Quilty, J. On the applicability of maximum overlap discrete wavelet transform integrated with MARS and M5 model tree for monthly pan evaporation prediction. Agric. For. Meteorol. 2019, 278, 107647. [CrossRef]

51. Adnan, R.M.; Yuan, X.; Kisi, O.; Anam, R. Improving accuracy of river flow forecasting using LSSVR with gravitational search algorithm. Adv. Meteorol. 2017, 2017, 1-23. [CrossRef]

52. Kisi, Ö.; Yildirim, G. Discussion of "Forecasting of reference evapotranspiration by artificial neural networks" by Slavisa Trajkovic, Branimir Todorovic, and Miomir Stankovic. J. Irrig. Drain. Eng. 2005, 131, 390-391. [CrossRef]

53. Mehdizadeh, S.; Behmanesh, J.; Khalili, K. Using MARS, SVM, GEP and empirical equations for estimation of monthly mean reference evapotranspiration. Comput. Electron. Agric. 2017, 139, 103-114. [CrossRef]

54. Kisi, O. Modeling reference evapotranspiration using three different heuristic regression approaches. Agric. Water Manag. 2016, 169, 162-172. [CrossRef]

55. Keshtegar, B.; Mert, C.; Kisi, O. Comparison of four heuristic regression techniques in solar radiation modeling: Kriging method vs RSM, MARS and M5 model tree. Renew. Sustain. Energy Rev. 2018, 81, 330-341. [CrossRef]

56. Keshtegar, B.; Kisi, O. RM5Tree: Radial basis M5 model tree for accurate structural reliability analysis. Reliab. Eng. Syst. Saf. 2018, 180, 49-61. [CrossRef]

57. Kisi, O.; Kilic, Y. An investigation on generalization ability of artificial neural networks and M5 model tree in modeling reference evapotranspiration. Theor. Appl. Climatol. 2015, 126, 413-425. [CrossRef]

58. Rahimikhoob, A. Comparison between M5 model tree and neural networks for estimating reference evapotranspiration in an arid environment. Water Resour. Manag. 2014, 28, 657-669. [CrossRef]

59. Amanifard, N.; Nariman-Zadeh, N.; Farahani, M.H.; Khalkhali, A. Modelling of multiple short-length-scale stall cells in an axial compressor using evolved GMDH neural networks. Energy Convers. Manag. 2008, 49, 2588-2594. [CrossRef]

60. Ivakhnenko, A.G. Polynomial theory of complex systems. IEEE Trans. Syst. ManCybern. 1971, SMC-1, 364-378. [CrossRef]

61. Ivakhnenko, A.G.; Ivakhnenko, G.A. Problems of further development of the group method of data handling algorithms. Part I. Pattern Recognit. Image Anal. C/C Raspoznavaniye Obraz. I Anal. Izobr. 2000, 10, 187-194.

62. Adnan, R.M.; Liang, Z.; Heddam, S.; Zounemat-Kermani, M.; Kisi, O.; Li, B. Least square support vector machine and multivariate adaptive regression splines for streamflow prediction in mountainous basin using hydro-meteorological data as inputs. J. Hydrol. 2020, 586, 124371. [CrossRef]

63. Roy, S.S.; Roy, R.; Balas, V.E. Estimating heating load in buildings using multivariate adaptive regression splines, extreme learning machine, a hybrid model of MARS and ELM. Renew. Sustain. Energy Rev. 2018, 82, 4256-4268. [CrossRef]

64. García Nieto, P.J.; García-Gonzalo, E.; Álvarez Antón, J.C.; Suárez, V.M.G.; Bayón, R.M.; Martín, F.M. A comparison of several machine learning techniques for the centerline segregation prediction in continuous cast steel slabs and evaluation of its performance. J. Comput. Appl. Math. 2018, 330, 877-895. [CrossRef] 
65. Pourghasemi, H.R.; Rahmati, O. Prediction of the landslide susceptibility: Which algorithm, which precision? CATENA 2018, 162, 177-192. [CrossRef]

66. Kuter, S.; Akyurek, Z.; Weber, G.-W. Retrieval of fractional snow covered area from MODIS data by multivariate adaptive regression splines. Remote Sens. Environ. 2018, 205, 236-252. [CrossRef]

67. Zhang, W.; Zhang, R.; Goh, A.T.C. Multivariate adaptive regression splines approach to estimate lateral wall deflection profiles caused by braced excavations in clays. Geotech. Geol. Eng. 2017. [CrossRef]

68. Jekabsons, G. ARESLab: Adaptive Regression Splines Toolbox for Matlab/Octave Ver. 1.13.0; Riga Technical University: Riga, Latvia, 2016.

69. Afsarian, F.; Saber, A.; Pourzangbar, A.; Olabi, A.G.; Khanmohammadi, M.A. Analysis of recycled aggregates effect on energy conservation using M5' model tree algorithm. Energy 2018, 156, 264-277. [CrossRef]

70. García Nieto, P.J.; García-Gonzalo, E.; Sánchez, A.B.; Miranda, A.A.R. Air quality modeling using the PSO-SVM-based approach, MLP neural network, and M5 model tree in the metropolitan area of oviedo (Northern Spain). Environ. Modeling Assess. 2017, 23, 229-247. [CrossRef]

71. Avval, Y.J.; Derakhshani, A. New formulas for predicting liquefaction-induced lateral spreading: Model tree approach. Bull. Eng. Geol. Environ. 2018, 78, 3649-3661. [CrossRef]

72. Deo, R.C.; Downs, N.; Parisi, A.V.; Adamowski, J.F.; Quilty, J.M. Very short-term reactive forecasting of the solar ultraviolet index using an extreme learning machine integrated with the solar zenith angle. Environ. Res. 2017, 155, 141-166. [CrossRef]

73. Pham, H.T.; Marshall, L.; Johnson, F.; Sharma, A. Deriving daily water levels from satellite altimetry and land surface temperature for sparsely gauged catchments: A case study for the Mekong River. Remote Sens. Environ. 2018, 212, 31-46. [CrossRef]

74. Lin, L.; Wang, Q.; Sadek, A.W. A combined M5P tree and hazard-based duration model for predicting urban freeway traffic accident durations. Accid. Anal. Prev. 2016, 91, 114-126. [CrossRef] [PubMed]

75. Singh, G.; Sachdeva, S.N.; Pal, M. M5 model tree based predictive modeling of road accidents on non-urban sections of highways in India. Accid. Anal. Prev. 2016, 96, 108-117. [CrossRef] [PubMed]

76. Jekabsons, G. M5PrimeLab: M5'Regression Tree and Model Tree Ensemble Toolbox for Matlab/Octave Ver. 1.7.0.; Institute of Applied Computer Systems Riga Technical University: Riga, Latvia, 2016; Available online: http://www.cs.rtu.lv/jekabsons/Files/M5 PrimeLab.pdf (accessed on 20 December 2019).

77. Stephens, J.C.; Stewart, E.H. A comparison of procedures for computing evaporation and evapotranspiration. Publication 1963, 62, 123-133.

78. Hargreaves, G.H.; Samani, Z.A. Estimating potential evapotranspiration. J. Irrig. Drain. Div. 1982, 108, $225-230$.

79. Hargreaves, G.H.; Samani, Z.A. Reference crop evapotranspiration from temperature. Appl. Eng. Agric. 1985, 1, 96-99. [CrossRef]

80. Tiyasha, T.; Tung, M.; Yaseen, Z.M. A survey on river water quality modelling using artificial intelligence models: 2000-2020. J. Hydrol. 2020, 585, 124670. [CrossRef]

81. Adnan, R.M.; Yuan, X.; Kisi, O.; Yuan, Y.; Tayyab, M.; Lei, X. Application of soft computing models in streamflow forecasting. In Proceedings of the Institution of Civil Engineers-Water Management; Thomas Telford Ltd.: London, UK, 2019; Volume 172, No. 3; pp. 123-134.

82. Bhagat, S.K.; Tung, T.M.; Yaseen, Z.M. Development of artificial intelligence for modeling wastewater heavy metal removal: State of the art, application assessment and possible future research. J. Clean. Prod. 2019, 250, 119473. [CrossRef] 